\title{
Strategic Asset Allocatoin with Liabilities: Beyond Stocks and Bonds
}

Citation for published version (APA):

Hoevenaars, R. P. P. M., Molenaar, R. D. J., Schotman, P. C., \& Steenkamp, T. B. M. (2008). Strategic Asset Allocatoin with Liabilities: Beyond Stocks and Bonds. Journal of Economic Dynamics \& Control, 32(9), 2939-2970. https://doi.org/10.1016/j.jedc.2007.11.003

Document status and date:

Published: 01/01/2008

DOI:

10.1016/j.jedc.2007.11.003

Document Version:

Publisher's PDF, also known as Version of record

Document license:

Taverne

Please check the document version of this publication:

- A submitted manuscript is the version of the article upon submission and before peer-review. There can be important differences between the submitted version and the official published version of record.

People interested in the research are advised to contact the author for the final version of the publication, or visit the DOI to the publisher's website.

- The final author version and the galley proof are versions of the publication after peer review.

- The final published version features the final layout of the paper including the volume, issue and page numbers.

Link to publication

\footnotetext{
General rights rights.

- You may freely distribute the URL identifying the publication in the public portal. please follow below link for the End User Agreement:

www.umlib.nl/taverne-license

Take down policy

If you believe that this document breaches copyright please contact us at:

repository@maastrichtuniversity.nl

providing details and we will investigate your claim.
}

Copyright and moral rights for the publications made accessible in the public portal are retained by the authors and/or other copyright owners and it is a condition of accessing publications that users recognise and abide by the legal requirements associated with these

- Users may download and print one copy of any publication from the public portal for the purpose of private study or research.

- You may not further distribute the material or use it for any profit-making activity or commercial gain

If the publication is distributed under the terms of Article $25 \mathrm{fa}$ of the Dutch Copyright Act, indicated by the "Taverne" license above, 


\title{
Strategic asset allocation with liabilities: Beyond stocks and bonds
}

\author{
Roy P.M.M. Hoevenaars ${ }^{\mathrm{a}, *}$, Roderick D.J. Molenaar ${ }^{\mathrm{b}}$, \\ Peter C. Schotman ${ }^{a}$, Tom B.M. Steenkamp ${ }^{c}$ \\ ${ }^{a}$ Faculty of Economics and Business Administration, University of Maastricht, \\ P.O. Box 616, 6200 MD Maastricht, The Netherlands \\ ${ }^{\mathrm{b}}$ ABP Investments, P.O. Box 75753, $1118 \mathrm{ZX}$ Schiphol, The Netherlands \\ ${ }^{\mathrm{c}}$ Vrije University Amsterdam, De Boelelaan 1105, $1081 \mathrm{HV}$ Amsterdam, The Netherlands
}

Received 1 July 2005; accepted 14 November 2007

Available online 14 December 2007

\begin{abstract}
This paper studies the strategic asset allocation for an investor with risky liabilities which are subject to inflation and real interest rate risk and who invests in stocks, government bonds, corporate bonds, T-bills, listed real estate, commodities and hedge funds. Using a vector autoregression for returns, liabilities and macro-economic state variables the paper explores the intertemporal covariance structure of assets and liabilities. We find horizon effects in time diversification, risk diversification, inflation hedge and real interest rate qualities. The covariance structure gives insights into which asset classes have a term structure of risk that is different from that of stocks and bonds. The alternative assets classes add value for long-term investors. Differences in strategic portfolios for asset-only and asset-liability investors are due to differences in the global minimum variance and
\end{abstract}

\footnotetext{
The views expressed in this paper are those of the authors and do not necessarily reflect those of our employer and our colleagues.

*Corresponding author. Tel.: + 31433883838 .

E-mail address: r.hoevenaars@ke.unimaas.nl (R.P.M.M. Hoevenaars).
} 
liability hedge portfolio. We find that the benefits of long-term investing are larger when there are liabilities.

(C) 2008 Elsevier B.V. All rights reserved.

JEL classification: C32; G11; G23

Keywords: Portfolio choice; Strategic asset allocation; Asset-liability management; Pension funds

\section{Introduction}

In making their strategic portfolio decisions, pension funds are restricted by their liabilities. At the same time pension funds and other institutional investors can choose from a large menu of alternative asset classes that goes beyond the traditional T-bills, bonds and stocks. In this paper we extend the existing models for strategic asset allocation. We study the problem of an investor with risky liabilities that are subject to inflation and interest rate risk, who invests in stocks, government bonds, corporate bonds, T-bills, listed real estate, commodities and hedge funds.

Liabilities are a predetermined component in the institutional investor's portfolio. Since liabilities are subject to real interest rate risk and inflation risk, assets that hedge against long-term liabilities risk are valuable for an institutional investor. The hedging demand for alternative asset classes like credits, commodities, hedge funds and real estate will depend on the covariance between assets and liabilities at different horizons.

Our interest is in three questions: (i) What do the time series properties of returns on assets and liabilities imply for the covariances at different investment horizons? (ii) Do the alternative asset classes add value for long-term investors? (iii) What do these covariances imply for the difference between the strategic portfolio of assetonly and asset-liability investors? We examine time and risk diversification properties and also the inflation hedge and real interest rate hedging qualities of the different assets. We investigate how the investment horizon influences the importance of the liabilities, and in particular whether the benefits from long-term investing are larger when there are liabilities.

To answer the first and second questions, we derive the covariance structure of assets and liabilities from a vector-autoregressive model for returns and other state variables. The 'term structure of risk', introduced by Campbell and Viceira (2005a), is a convenient tool for demonstrating the implications of asset price dynamics at different investment horizons. This term structure shows the evolution of the annualized covariance matrix of returns as a function of the investment horizon. The covariance structure reveals which alternative asset classes have a term structure of risk that is markedly different from that of stocks and bonds.

We find that the covariance structure exhibits horizon effects regarding the inflation hedge and interest hedging qualities of the additional assets. Commodities help in hedging inflation risk, as they move closely with inflation in the short and long run. Since in addition commodities have little correlation with stocks and 
bonds, they have the best risk diversifying properties among the assets in our universe. Hedge funds have good inflation hedging qualities in the long run, but also much exposure to stocks and bonds. Term structure properties of listed real estate are mostly captured by traditional asset classes such as stocks and bonds. Credits are similar to bonds: inflation hedging qualities of both credits and bonds are good in the long run, but poor in the short run. Both asset classes also have good real interest rate hedging qualities. In summary, alternative asset classes are important for a longterm investor with liabilities - more so than for an asset-only investor.

For the third question, we consider the portfolio problem of an investor with a long horizon whose preferences are defined on the funding ratio. We derive the strategic hedging demands of the investor using the log-linear approximations of Campbell and Viceira (2002, 2005a). Empirically, the main difference between the asset-only and asset-liability perspective is the attractiveness of short-term T-bills. Asset-only investors have strong demand for short-term instruments due to their low risk. Asset-liability investors shun T-bills due to the duration mismatch with the liabilities. T-bills do not provide a hedge against the long real interest rate risk in the liabilities. Nevertheless T-bills remain a good risk diversifier in a portfolio of stocks and bonds and are a good inflation hedge. We also find that the horizon effects are stronger for the asset-liability investor than for the asset-only investor. Therefore the benefits from long-term investing are greater when there are liabilities.

Our paper contributes to three strands of the literature: strategic asset allocation, asset-liability management, and the behavior of alternative asset classes. In the literature on strategic asset allocation many studies have shown that long-term decisions differ markedly from short-term portfolio rules if the investment opportunity set varies over time and the state variables that predict returns have strong autocorrelations. Brennan and Xia (2002), Lioui and Poncet (2001), BajeuxBesnainou et al. (2003), Barberis (2000), Wachter (2002), Campbell et al. (2004), Campbell et al. (2003) are a few examples of studies that consider the long-term investor problem in different settings using variations in preferences and return dynamics. These studies consider the asset-only investor and an asset menu consisting of T-bills, bonds and stocks. This paper explores the impact of timevarying expected returns of the alternative assets. Furthermore we investigate what the time-varying investment opportunities imply for the difference between the strategic portfolio of asset-only and asset-liability investors.

Until recently, almost all regulatory frameworks and accounting standards did not require fair valuation of pension liabilities. As a consequence, strategic asset allocation decisions were commonly considered in an asset-only context. The recent shift towards fair valuation of pension liabilities has led to a revived interest in ways to deal with interest and inflation risk in an optimal portfolio choice.

In an asset-liability model Leibowitz (1987) and Sharpe and Tint (1990) introduce a single-period surplus optimization framework when there are pension liabilities. In a long-horizon model Sundaresan and Zapatero (1997) solve the asset allocation of a pension plan and relate it to the marginal productivity of workers in the firm. They consider constant investment opportunities in a risky and riskless asset. Closest to our paper is Van Binsbergen and Brandt (2008) who allow for time-varying 
investment opportunities in stocks, bonds and T-bills in an asset-liability management problem. They explicitly model the tradeoff between the long-term objective of maximizing the funding ratio and satisfying short-term risk constraints. Our paper differs in two ways. First, our emphasis is on the alternative asset classes. Second, our liabilities are like a real bond, whereas Van Binsbergen and Brandt (2008) treat the liabilities as a nominal bond.

Properties of alternative asset classes have mostly been studied in isolation. For example, Gorton and Rouwenhorst (2006) produce stylized facts about commodity futures. Froot (1995) argues that listed real estate does not add much value in an already well-diversified portfolio. Fugazza et al. (2007), however, find a considerable role for European listed real estate in a strategic portfolio with stocks, bonds and cash. Many authors focus on the heterogeneity of hedge fund performance, risk characteristics and biases (Fung and Hsieh, 1997; Ackermann et al., 1999; Agarwal and Naik, 2000; Fung and Hsieh, 2000). Literature on corporate bonds examines and explains credit spreads (Elton et al., 2001; Fama, 1981). In this paper we focus on the added value of these alternative asset classes in a portfolio with stocks, bonds and T-bills.

The structure of the paper is as follows. Section 2 defines the portfolio choice problem. Section 3 describes the return dynamics and presents the estimation results of the VAR. Section 4 explores the covariance structure of the assets, liabilities and inflation at different horizons. Section 5 examines the portfolios of asset-only and asset-liability investors. Section 6 concludes.

\section{Portfolio choice}

The asset allocation of an institutional investor is largely driven by long-run liabilities. A defined-benefit pension fund promises to pay benefits related to some function of lifetime earnings of participants. Liabilities depend on past and expected future earnings of participants, the term structure of interest rates, demographics and mortality rates. Markets are incomplete in the sense that the available asset classes cannot fully hedge the liabilities. The main source of the incompleteness is the inflation dependence of the liabilities. ${ }^{1}$ The pension fund invests contributions by participants and the plan sponsor. In order to meet the liabilities in the long-run, the fund needs to take risk and earn a risk premium. We extend the usual asset menu of the traditional categories of bills, bonds and stocks to include the alternative assets classes (listed) real estate, hedge funds, commodities and corporate bonds.

Following Leibowitz et al. (1994) we approach asset-liability management from a funding ratio return perspective. The funding ratio $(F)$ is defined as the ratio of assets $(A)$ to liabilities $(L)$. The funding ratio $\log$-return $r_{F}$ is then defined as the return of

\footnotetext{
${ }^{1}$ The best hedge against the inflation risk would be index-linked bonds. Since the market for inflation indexed bonds is small relative to the size of the pension liabilities, we exclude them from the analysis. So implicitly we assume an incomplete market with respect to inflation.
} 
the assets minus the return on the liabilities,

$$
r_{F, t}=r_{A, t}-r_{L, t},
$$

where $r_{A, t}$ is the return of the asset portfolio and $r_{L, t}$ the return on the liabilities. All returns are defined in real terms, in excess of realized inflation $\pi_{t}$. Logarithmic returns for asset class $i$ are denoted by $r_{i t}$ and excess returns are defined relative to the real return on T-bills $\left(r_{t b, t}\right)$ as $x_{i t}=r_{i t}-r_{t b, t}$. The logarithmic excess return on the liabilities are denoted $x_{L, t}=r_{L, t}-r_{t b, t}$. All excess returns are collected in the vector,

$$
x_{t}=\left(\begin{array}{c}
x_{A, t} \\
x_{L, t}
\end{array}\right) \text {. }
$$

In the next section we model the predictable component of the excess returns in detail. To evaluate the mean and variance of the $\tau$-period returns we define the annualized expected returns

$$
\mu_{t}^{(\tau)}=\frac{1}{\tau} \mathrm{E}_{t}\left[x_{t+\tau}^{(\tau)}\right]=\left(\begin{array}{c}
\mu_{A, t}^{(\tau)} \\
\mu_{L, t}^{(\tau)}
\end{array}\right),
$$

and the annualized covariance matrix

$$
\Sigma^{(\tau)}=\frac{1}{\tau} \operatorname{Var}_{t}\left[x_{t+\tau}^{(\tau)}\right]=\left(\begin{array}{cc}
\Sigma_{A A}^{(\tau)} & \sigma_{A L}^{(\tau)} \\
\sigma_{A L}^{(\tau)} & \sigma_{L}^{(\tau) 2}
\end{array}\right),
$$

where the notation $x_{t+\tau}^{(\tau)}$ denotes the cumulative excess return over $\tau$ periods. This relation between $\tau$ and $\Sigma^{(\tau)}$ is the term structure of risk introduced by Campbell and Viceira (2005a), here extended to include the liabilities and alternative asset classes. Estimating $\Sigma^{(\tau)}$ will be the main purpose of the econometric time series analysis of the returns. More specifically we are interested in the term structure of risk of the alternative assets and in the covariance $\sigma_{A L}^{(\tau)}$ of assets and liabilities. The latter determines the hedge potential of different asset classes at different horizons.

The term structure of risk provides many insights in the relative importance of different assets for an institutional investor. To obtain portfolio weights, we need a few more steps. The investor chooses a portfolio $\alpha_{t}$ of the risky assets and invests the remainder fraction of wealth $1-\imath^{\prime} \alpha_{t}$ in the T-bills. Campbell and Viceira $(2002,2005 a, b)$ provide the following log-linear approximation to the portfolio return,

$$
r_{A, t+1}=r_{t b, t+1}+\alpha_{t}^{\prime}\left(x_{A, t+1}+\frac{1}{2} \sigma_{A}^{2}\right)-\frac{1}{2} \alpha_{t}^{\prime} \Sigma_{A A} \alpha_{t},
$$

where $\sigma_{A}^{2}$ is the vector with the diagonal elements of $\Sigma_{A A}$. As Van Binsbergen and Brandt (2008) we assume CRRA preferences on the funding ratio at some future date $T=t+\tau$,

$$
V_{t}^{(\tau)}=\max _{\left\{\alpha_{t}, \ldots, \alpha_{T-1}\right\}} \mathrm{E}_{t}\left[\frac{F_{T}^{1-\gamma}}{1-\gamma}\right] .
$$


Van Binsbergen and Brandt (2008) proceed by numerically solving the dynamic programming problem (5) under short-sell constraints and with penalties for violating short-term value-at-risk constraints. We opt for approximate analytical portfolio weights.

It has been widely documented that portfolio choice models produce erratic outcomes the larger the number of assets included. With more than a few assets optimized portfolios overestimate the investment opportunities and portfolio weights become very sensitive to minor estimation errors in expected returns. In our case we have seven asset classes plus the liabilities portfolio. With this expanded asset space the danger of error-maximization is large. ${ }^{2}$

Many suggestions have been made to avoid the erratic portfolio choice. Most common are restrictions on portfolio weights and informative Bayesian priors. In the cross-sectional portfolio choice literature, Black and Litterman (1992), Pastor and Stambaugh (2000), Jorion (1986) and many others have suggested priors that shrink the portfolio weights towards an asset pricing model, the market portfolio or the global minimum variance (GMV) portfolio. Likewise, Wachter and Warusawitharana (2008) explore Bayesian priors on the predictability of equity returns. They conclude that informative priors improve out-of-sample performance of myopic market timing.

We stabilise the portfolio weights by assuming that the investor plans to hold constant proportions of his wealth in each of the asset classes for $\tau$ periods. Fixed portfolio weights also appear more closely connected to the industry practice. Pension funds commonly plan their strategic portfolio on a constant mix basis. The typical strategic investment plan of an institutional investor has a long horizon and is only reviewed once every three to five years. After performing an ALM study the fund defines a strategic mix over asset classes, while allowing various tactical bets depending on short term market views.

One way of implementing this assumption is to set the expected returns $\mu_{A, t}^{(\tau)}$ and $\mu_{L, t}^{(\tau)}$ constant over the investment horizon. Under this assumption maximization of (5) implies mean-variance portfolios as in Campbell and Viceira $(2005 \mathrm{a}, \mathrm{b}){ }^{3}$ Substituting (4) in (1),

$$
r_{F, t+1}=\alpha_{t}^{\prime}\left(x_{A, t+1}+\frac{1}{2} \sigma_{A}^{2}\right)-x_{L, t+1}-\frac{1}{2} \alpha_{t}^{\prime} \Sigma_{A A} \alpha_{t} .
$$

\footnotetext{
${ }^{2}$ See Kan and Zhou (2007) for recent analytical results. DeMiguel et al. (2008) empirically establish that optimized portfolios do not outperform a naive equally weighted portfolio out-of-sample. Litterman (2003, Chapter 9, 10) illustrates the problem in an ALM setting and proposes to replace the estimated expected returns from a return model based on historical data by more plausible expected returns that do not imply extreme portfolio weights. The phrase 'error maximization' has been coined by Michaud (1989) to describe the extreme sensitivity of portfolio weights to estimation errors in expected returns.

${ }^{3}$ With constant expected returns the dynamic programming solution of (5) is still different from the static mean-variance solution. Under the maintained assumption that $\Sigma^{(\tau)}$ depends on the investment horizon, the investor still wants to adjust her portfolio as the horizon shrinks. In presenting the static portfolio weights we ignore this element, which is tantamount to assuming that the horizon $\tau$ remains constant and the terminal date $T$ shifts forward every period. This seems in line with an actual pension fund which does not have a fixed terminal date $\tau$.
} 
One-period portfolio returns are aggregated assuming that the investor rebalances to the initial weights at the end of each period. Starting from the one-period log return (6), aggregation to the $\tau$-period return with fixed, horizon specific, portfolio weight $\alpha_{t}^{(\tau)}$ gives

$$
r_{F, t+\tau}^{(\tau)}=\sum_{j=1}^{\tau} r_{F, t+j}=\alpha_{t}^{(\tau)^{\prime}}\left(x_{A, t+\tau}^{(\tau)}+\frac{\tau}{2} \sigma_{A}^{2}\right)-\frac{\tau}{2} \alpha_{t}^{(\tau)^{\prime}} \Sigma_{A A} \alpha_{t}^{(\tau)}-x_{L, t+\tau}^{(\tau)} .
$$

Evaluating the mean and variance of the $\tau$-period returns we find

$$
\begin{aligned}
& \mathrm{E}_{t}\left[r_{F, t+\tau}^{(\tau)}\right]=\tau\left(\alpha_{t}^{(\tau)^{\prime}}\left(\mu_{A, t}^{(\tau)}+\frac{1}{2} \sigma_{A}^{2}\right)-\frac{1}{2} \alpha_{t}^{(\tau)^{\prime}} \Sigma_{A A} \alpha_{t}^{(\tau)}-\mu_{L, t}^{(\tau)}\right), \\
& \operatorname{Var}_{t}\left[r_{F, t+\tau}^{(\tau)}\right]=\tau\left(\sigma_{L}^{(\tau) 2}-2 \alpha_{t}^{(\tau)^{\prime}} \sigma_{A L}^{(\tau)}+\alpha_{t}^{(\tau)^{\prime}} \Sigma_{A A}^{(\tau)} \alpha_{t}^{(\tau)}\right) .
\end{aligned}
$$

We refer to the volatility of the funding ratio return as the mismatch risk. Assuming normality of the excess returns, the optimization problem (5) reduces to

$$
\max _{\alpha_{t}^{(\tau)}} \mathrm{E}_{t}\left[r_{F, t+\tau}^{(\tau)}\right]+\frac{1}{2}(1-\gamma) \operatorname{Var}_{t}\left[r_{F, t+\tau}^{(\tau)}\right]
$$

implying that the asset-liability investor follows a mean-variance optimal investment strategy. Differentiating (10) we obtain the optimal portfolio as

$$
\alpha_{t}^{(\tau)}=\frac{1}{\gamma}\left(\left(1-\frac{1}{\gamma}\right) \Sigma_{A A}^{(\tau)}+\frac{1}{\gamma} \Sigma_{A A}\right)^{-1}\left(\mu_{t}^{(\tau)}+\frac{1}{2} \sigma_{A}^{2}-(1-\gamma) \sigma_{A L}^{(\tau)}\right) .
$$

The portfolio has two components: the speculative portfolio

$$
\alpha_{S, t}^{(\tau)}=\frac{1}{\gamma}\left(\left(1-\frac{1}{\gamma}\right) \Sigma_{A A}^{(\tau)}+\frac{1}{\gamma} \Sigma_{A A}\right)^{-1}\left(\mu_{A, t}^{(\tau)}+\frac{1}{2} \sigma_{A}^{2}\right)
$$

and the liability hedging demand

$$
\alpha_{H}^{(\tau)}=\left(1-\frac{1}{\gamma}\right)\left(\left(1-\frac{1}{\gamma}\right) \Sigma_{A A}^{(\tau)}+\frac{1}{\gamma} \Sigma_{A A}\right)^{-1} \sigma_{A L}^{(\tau)} .
$$

The decomposition of the total portfolio in speculative and hedging demand is similar to other strategic portfolio decompositions in the literature as reviewed in Campbell and Viceira (2002). The hedge portfolio usually arises due to changes in the investment opportunity set. The liability hedge portfolio (LHP) is different, since it is related to the covariance between assets and liabilities and exists even if returns are not predictable.

Under our assumptions the hedging demand does not depend on time. It is horizon dependent through the term structure of covariances of asset and liability returns. For large $\gamma$ the hedging demand reduces to

$$
\lim _{\gamma \rightarrow \infty} \alpha_{H}^{(\tau)}=\left(\Sigma_{A A}^{(\tau)}\right)^{-1} \sigma_{A L}^{(\tau)}
$$

which is the portfolio that minimizes the mismatch risk (9). The quantities $\alpha_{H}^{(\tau)}$, and its building blocks $\Sigma_{A A}^{(\tau)}$ and $\sigma_{A L}^{(\tau)}$, will be our main focus in the remainder of the paper. 
We also consider the costs of suboptimal portfolios. We use the certainty equivalent to evaluate the economic loss of deviating from the optimal strategic asset allocation. We define the economic loss of holding some sub-optimal portfolio $a$ by computing the percentage riskfree return the investor requires as a compensation for holding the sub-optimal portfolio instead of the optimal portfolio $\alpha^{(\tau)}$ in (11). It is computed as the difference between the mean-variance utility of the two portfolios. Let $\hat{q}_{t}^{(\tau)}$ be the optimal value of the mean-variance function (10), and let $q_{t}^{(\tau)}$ be the mean-variance utility for the arbitrary portfolio $a$. Subtracting the two utility values and expressing the result in an annualized percentage gives

$$
\begin{aligned}
f_{t}^{(\tau)}= & \frac{1}{\tau}\left(\hat{q}_{t}^{(\tau)}-q_{t}^{(\tau)}\right) \\
= & \left(\alpha^{(\tau)}-a\right)^{\prime}\left(\mu_{t}^{(\tau)}+\frac{1}{2} \sigma_{A}^{2}\right)-(1-\gamma)\left(\alpha^{(\tau)}-a\right)^{\prime} \sigma_{A L}^{(\tau)} \\
& +\frac{1}{2} \gamma\left(a^{\prime} \Sigma_{A A}^{(\tau)} a-\alpha^{(\tau)^{\prime}} \Sigma_{A A}^{(\tau)} \alpha^{(\tau)}\right)+\eta^{(\tau)} .
\end{aligned}
$$

The first two components on the right-hand side attribute the certainty equivalent to compensations for return enhancement and for the liability hedge potential. The third component is the difference in the long-run variance of the two portfolios. The final term,

$$
\eta^{(\tau)}=\frac{1}{2}\left(a^{\prime}\left(\Sigma_{A A}-\Sigma_{A A}^{(\tau)}\right) a-\alpha^{(\tau)^{\prime}}\left(\Sigma_{A A}-\Sigma_{A A}^{(\tau)}\right) \alpha^{(\tau)}\right),
$$

is a small remainder term due to the differences in the Jensen inequality corrections in aggregating the asset returns over time. All components in (15) are horizon dependent. The relative weights of the three main components depend on the level of risk aversion. For highly risk averse investors the costs of poor matching and diversification will dominate and portfolios that deviate from the portfolio with minimum mismatch risk will be costly.

For an asset-only investor the mean-variance optimization is equivalent to a second-order approximation of maximizing expected utility of final period wealth,

$$
V_{t}^{(\tau)}=\max \mathrm{E}_{t}\left[\frac{W_{t+\tau}^{1-\gamma}}{1-\gamma}\right]
$$

From the formulation (16) and the definition of $r_{A, t+j}$ in (4) it follows that the optimal portfolio of the asset-only investor is given by

$$
\alpha_{A O}^{(\tau)}=\frac{1}{\gamma}\left(\left(1-\frac{1}{\gamma}\right) \Sigma_{A A}^{(\tau)}+\frac{1}{\gamma} \Sigma_{A A}\right)^{-1}\left(\mu_{t}^{(\tau)}+\frac{1}{2} \sigma_{A}^{2}+(1-\gamma) \sigma_{A r}^{(\tau)}\right),
$$

where $\sigma_{A r}^{(\tau)}$ is the vector of covariances between excess returns and the benchmark T-bill return over an horizon of $\tau$ periods. The speculative component of the asset-liability investor is the same as for the asset-only investor. The difference is in the hedging component of the portfolio. The asset-only portfolio contains the covariance $\sigma_{A r}^{(\tau)}$, whereas the asset-LHP in (11) uses $-\sigma_{A L}^{(\tau)}$. The best liability hedging portfolio corresponds to minimizing the mismatch risk (14) instead of the 
stand-alone risk of the asset mix. The difference in sign between (17) and (11) is due to the short position in the liabilities instead of the long position in the T-bill. Liabilities are not an investable asset themselves. The asset-liability investor invests in the risky assets, but cannot invest in the risky benchmark.

\section{Return dynamics}

The return dynamics extend the vector autoregressions in Campbell and Viceira (2005a) and Campbell et al. (2003) in two ways. First, we include more asset classes. Campbell et al. (2003) include real returns on stocks, bonds and bills. We augment this set with credits and alternatives (i.e. listed real estate, commodities and hedge funds). We also add the credit spread as an additional state variable driving expected returns. Second, we introduce risky liabilities to the VAR. These liabilities are like inflation-linked coupon bonds. Their returns follow the return of long-term real bonds. Below we describe the model, the data and estimation results.

\subsection{Model}

The dynamics of assets and liabilities follow a first-order VAR for quarterly data. Specifically, let

$$
z_{t}=\left(\begin{array}{c}
r_{t b, t} \\
s_{t} \\
x_{t}
\end{array}\right),
$$

where $r_{t b, t}$ and $x_{t}$ have been defined in Section 2 and $s_{t}$ is a vector of other state variables that predict $r_{t b}$ and elements of $x_{t}$. The vector with state variables $s_{t}$ contains four predictive variables: the nominal 3-months interest rate $\left(r_{\text {nom }}\right)$, the dividend-price ratio $(d p)$, the term spread $(s p r)$ and the credit spread $(c s)$. Altogether the VAR contains $1+4+7=12$ variables.

For most time series quarterly data are available for the period 1952:II to 2005:IV. The exceptions are the alternative asset classes, for which the historical data start at a much later date. Because of the large dimension of the VAR, and due to the missing data for the early part of the sample, we cannot obtain reliable estimates with an unrestricted VAR. We therefore impose a number of exclusion restrictions to reduce the number of parameters. These restrictions also enable us to implement the efficient estimator of Stambaugh (1997) to deal with time series with unequal length.

We split the vector of excess returns in two parts,

$$
x_{t}=\left(\begin{array}{l}
x_{1, t} \\
x_{2, t}
\end{array}\right),
$$

where $x_{1}$ contains the quarterly excess returns on stocks $\left(x_{s}\right)$ and bonds $\left(x_{b}\right)$, and $x_{2}$ contains the excess returns on credits $\left(x_{\mathrm{cr}}\right)$, commodities $\left(x_{\mathrm{cm}}\right)$, hedge funds $\left(x_{h}\right)$, listed real estate $\left(x_{\mathrm{re}}\right)$, and the liabilities $\left(x_{L}\right)$. The variables in $x_{1}$ are the assets that 
are also included in the model of Campbell et al. (2003). The variables in $x_{2}$ are the additional asset classes.

The restrictions on the VAR concern the vector $x_{2}$. The additional assets are assumed to provide no dynamic feedback to the basic assets and state variables. For the subset of variables,

$$
y_{t}=\left(\begin{array}{c}
r_{t b, t} \\
s_{t} \\
x_{1, t}
\end{array}\right) \text {, }
$$

we specify the subsystem unrestricted VAR

$$
y_{t+1}=a+B y_{t}+\varepsilon_{t+1},
$$

where $\varepsilon_{t+1}$ has mean zero and covariance matrix $\sum_{\varepsilon \varepsilon}$. For the variables in $x_{2}$ we use the model

$$
x_{2, t+1}=c+D_{0} y_{t+1}+D_{1} y_{t}+H x_{2, t}+\eta_{t+1},
$$

where $D_{0}$ and $D_{1}$ are unrestricted $(4 \times 8)$ matrices, and $H=\operatorname{diag}\left(h_{1}, \ldots, h_{4}\right)$ is a diagonal matrix. The diagonal form of $H$ implies that $x_{2 i, t}$ only affects the expected return of itself, but not of the other additional assets in $x_{2}$. The shocks $\eta_{t}$ have zero mean and a diagonal covariance matrix $\Omega$. Contemporaneous covariances are captured by $D_{0}$. Without loss of generality we can therefore set the covariance of $\eta_{t}$ and $\varepsilon_{t}$ equal to zero.

Combining Eqs. (18) and (19) the complete VAR can be written as

$$
z_{t+1}=\boldsymbol{\Phi}_{0}+\boldsymbol{\Phi}_{1} z_{t}+u_{t+1}
$$

where

$$
\boldsymbol{\Phi}_{0}=\left(\begin{array}{c}
a \\
c+D_{0} a
\end{array}\right), \quad \boldsymbol{\Phi}_{1}=\left(\begin{array}{cc}
B & \mathbf{0} \\
D_{1}+D_{0} B & H
\end{array}\right),
$$

and $u_{t}$ has covariance matrix

$$
\boldsymbol{\Sigma}=\left(\begin{array}{cc}
\Sigma_{\varepsilon \varepsilon} & \sum_{\varepsilon \varepsilon} D_{0}^{\prime} \\
D_{0} \Sigma_{\varepsilon \varepsilon} & \Omega+D_{0} \Sigma_{\varepsilon \varepsilon} D_{0}^{\prime}
\end{array}\right)
$$

The form of (19), with the contemporaneous $y_{t+1}$ among the regressors, facilitates efficient estimation of the covariances between shocks in $y_{t}$ and $x_{2 t}$ when the number of observations in $x_{2 t}$ is smaller than in $y_{t}$. The full sample can be used for estimation of the core VAR (18), while each of the elements in $x_{2}$ is estimated using the available observations of the returns for that time series. This approach is based on Stambaugh (1997) and makes optimal use of all information in both the long and short time series. Furthermore it ensures that the estimate of $\boldsymbol{\Sigma}$ is positive semidefinite. As in Campbell and Viceira (2005a) we assume that the errors are homoskedastic.

Since some of the state variables are very persistent, they might well have a unit root. As in the models of Brennan et al. (1997), Campbell and Viceira (2002) and 
Campbell et al. (2003) we do not adjust the estimates of the VAR for possible small sample biases related to near non-stationarity of some series (see, for example, Stambaugh, 1999; Bekaert and Hodrick, 2001; Campbell and Yogo, 2006).

\subsection{Data}

We use quarterly US data. Most time series start in 1952:II; all series end in 2005:IV. However, the first observation for commodities is 1970:I. For hedge funds it is 1990:II, and for listed real estate data start in 1972:II.

The 90-days T-bill, the 20-years constant maturity yield and the credit yield (Moody's Seasoned Baa Corporate Bond Yield) are from the FRED website. ${ }^{4}$ In order to generate the yield and credit spread we obtain the zero yield data up to 1996:III from Campbell and Viceira (2002, Chapter 3). We have extended the series using data from FRED. For inflation we use the seasonally adjusted consumer price index for all urban consumers and all items also from the FRED website. Data on stock returns and the dividend-price ratio are based on the S\&P Composite and are from the 'Irrational Exuberance' data of Shiller. ${ }^{5}$ Credit returns are based on the Salomon Brothers long-term high-grade corporate bond index, and are obtained from Ibbotson (until 1994:IV) and Datastream. Hedge fund returns are based on the HFRI fund of funds conservative index return series. This equally weighted net-offees return index is broadly diversified across different style sectors. Fung and Hsieh (1997) and Ackermann et al. (1999) demonstrate that these hedge fund styles each exhibit different risk and return properties. Rather than accounting for this heterogeneity in investment styles, we focus on an index which represents the whole industry because we address hedge funds as an asset class. In the same way, commodities are represented as an asset class by the GSCI index. It is a composite index of all world-production weighted commodity sector returns. This total return index represents an unleveraged, long-only investment in fully collateralized nearby commodity futures with full reinvestment. The NAREIT North America return index represents listed real estate returns. This indirect market capitalization index represents total return behavior of publicly traded property companies on NYSE, AMEX, NASDAQ and Toronto stock exchange. All return series are logarithmic.

We construct the real gross nominal bond return series from 20 year constant maturity yields on US bonds using the approach described by Campbell and Viceira (2002),

$$
r_{b, t+1}=\frac{1}{4} y_{t+1}-D_{b, t}\left(y_{t+1}-y_{t}\right)-\pi_{t+1},
$$

where $y_{t}=\ln \left(1+Y_{t}\right)$ is the $\log$-yield on the 20 -year bond and $D_{b, t}$ the approximate duration. The liability return series is also based on the loglinear transformation (21), but using a real yield $r r_{t}$ and a different duration $D_{L}$,

$$
r_{L, t+1}=\frac{1}{4} r r_{t+1}-D_{L}\left(r r_{t+1}-r r_{t}\right) \text {. }
$$

\footnotetext{
${ }^{4}$ http://research.stlouisfed.org/fred2/.

${ }^{5}$ http://aida.econ.yale.edu/ shiller/data.htm.
} 
The real yield is the 10-year US real interest rate obtained from Bridgewater (proprietary data). The average duration of pension fund liabilities is assumed to be 17 years. To describe the liabilities of a pension fund as a constant maturity indexlinked bond we need to assume that the fund is in a stationary state and pays full indexation. A sufficient condition for this to be true is that the distribution of the age cohorts and the built-up pension rights per cohort are constant through time. Furthermore, we assume that the inflow from contributions equals the net present value of the new liabilities and that it also equals the current payments.

In defining the liabilities we ignore taxation issues as described in Black (1980) and Tepper (1981). We also do not consider actuarial risks such as longevity risk, ageing and changes in the characteristics of the participants and demographics. ${ }^{6}$ In this paper we assume inflation and interest rate risk are the only relevant risk factors for the pension fund. In particular the contribution rate adapts to changes in mortality rates, because we assume the inflow from contributions equals the net present value of new liabilities.

Return series of illiquid assets are often characterized by their high returns, low volatility and low correlation with other series. Hedge funds are a good example. Hedge funds often hold illiquid or over-the-counter investment products for which no publicly available trade prices exist. Fund managers may use the last available trade price as a proxy for the current price or intentionally smooth profits and losses by spreading them over several months, hereby reducing the volatilities and correlations. Underestimation of volatility can make an asset class more attractive than it actually is. Geltner $(1991,1993)$ discusses methods to unsmooth return series to make them comparable with the more liquid assets. He uses the autocorrelation in returns as a measure of illiquidity and proposes the unsmoothing filter

$$
r_{t}^{*}=\frac{r_{t}-\rho r_{t-1}}{1-\rho}
$$

where $r_{t}$ is the original smoothed return series, $\rho$ is the first-order autocorrelation coefficient and $r_{t}^{*}$ is the unsmoothed hedge fund return series which will be used in the VAR. For our hedge fund data $\rho=0.28$. The unsmoothed series have a more representative short-term volatility. For the long-term analysis the unsmoothing is not necessary as the VAR can take the autocorrelation into account. On the other hand, using the original smoothed series would seriously underestimate the short-term volatility.

Returns in a database of hedge funds are often subject to reporting biases. To correct for backfill bias we subtract an annual $2.15 \%$ from the published returns of the hedge fund series. ${ }^{7}$ The adjustment affects the average returns, but does not influence risk properties.

\footnotetext{
${ }^{6}$ In particular there is a revived interest in longevity risk. Blake et al. (2006) address ways how pension funds can hedge against aggregate longevity risk in the developing financial market of longevity bonds and swaps. Poterba (2001) and Goyal (2004) investigate the relationship between population age structure and stock returns.

${ }^{7}$ See Fung and Hsieh (2000) and Ackermann et al. (1999) for an overview on survivorship, termination, self-selection, liquidation, backfill and multiperiod sampling biases. The adjustment is the same as in Posthuma and Van der Sluis (2003) who show that the reported historical returns of hedge funds are on an annual basis too high.
} 
We include four predictor variables for the excess returns: the realised real T-bill return, the $\log$ of the dividend-price ratio of the S\&P Composite, the yield spread (difference between the $\log 10$-year zeros yield and the $\log 90$-day T-bill), and the credit spread (difference between the log BAA yield and the $\log 10$-years zero). These state variables are common in the literature. Campbell and Shiller $(1988,1991)$ are early references for the dividend-price ratio, the nominal short-term interest rate and the yield spread as predictive variables for stock returns. Brandt and Santa-Clara (2006) use the dividend yield, term spread, credit spread and the nominal T-bill rate. Campbell et al. (2003) and Campbell and Viceira (2005a) include the short-term nominal interest rate, yield spread and dividend-price ratio in the VAR. Furthermore, Campbell et al. (2003) find that shocks in the nominal short rate are strongly correlated with shocks in excess bond returns. In addition the yield spread is helpful in predicting future excess bond returns. Fama and French (1989) link the dividend yield, credit spread and yield spread to the business cycle. They argue that the risk premia for investing in bonds and corporate bonds are high in contraction periods and low in expansion periods, and that these risk premia are related to the yield spread and credit spread, respectively. The opposite applies to the dividend-price ratio, which is high in expansion periods and low in contraction periods. Instead of the dividend-price ratio many studies employ the price-earnings ratio or another fundamental price ratio. These usually have similar predictive power as the dividend-price ratio. ${ }^{8}$

Table 1 reports summary statistics from the data. Due to the different starting dates, the statistics must be interpreted with some care. Credits have a higher return than bonds. This is due to positive credit spreads and reflected in the higher Sharpe ratio. Elton et al. (2001) explain credit spreads as being positive for three reasons: a compensation for expected default loss; a tax premium which should be paid on corporate bonds but not on government bonds; and a risk premium for systematic risk. De Jong and Driessen (2008) also identify a liquidity risk premium in credit spreads. The average return on commodities is higher than that on stocks, but the higher volatility results in a lower Sharpe ratio. Although listed real estate is often seen as equivalent to equity, it has a lower return and higher volatility than stocks, which results in a lower Sharpe ratio of 0.29 . Just like stocks, listed real estate returns have negative skewness.

\subsection{Estimation results}

Table 2 reports the parameter estimates of the subsystem VAR in (18) on the full sample. Correlations and standard deviations of the innovations are given in Table 3.

The nominal interest rate, dividend-price ratio and credit spread have significant predictive power for excess stock returns. The negative correlation of shocks in the dividend-price ratio and credit spread with shocks in stocks returns imply that a positive innovation in the credit spread or dividend-price ratio has a negative effect

\footnotetext{
${ }^{8}$ The evidence on predictability is not uncontroversial. See Goyal and Welch (2003), Cochrane (2008) and Campbell and Thompson (2008) for opposing views on the issue.
} 
Table 1

Summary statistics

\begin{tabular}{|c|c|c|c|c|c|c|c|c|}
\hline & Mean & St dev & Sharpe & Min & Max & Skew & $X K$ & Start \\
\hline \multicolumn{9}{|l|}{ Excess returns } \\
\hline Stocks $\left(x_{s}\right)$ & 6.74 & 14.39 & 0.47 & -28.72 & 21.66 & -1.02 & 2.56 & 1952:II \\
\hline Bonds $\left(x_{b}\right)$ & 1.50 & 9.69 & 0.15 & -18.58 & 18.78 & 0.32 & 2.37 & 1952:II \\
\hline Credits $\left(x_{\mathrm{cr}}\right)$ & 1.80 & 8.73 & 0.21 & -17.07 & 18.15 & 0.07 & 2.67 & 1952:II \\
\hline Commodities $\left(x_{\mathrm{cm}}\right)$ & 7.52 & 18.94 & 0.40 & -23.86 & 42.03 & 0.29 & 1.79 & 1970:I \\
\hline Real estate $\left(x_{\mathrm{re}}\right)$ & 5.54 & 16.86 & 0.33 & -30.58 & 28.98 & -0.37 & 1.75 & 1972:II \\
\hline Hedge Funds $\left(x_{h}\right)$ & 2.07 & 5.29 & 0.39 & -10.01 & 8.62 & -0.88 & 3.58 & 1990:II \\
\hline Liabilities $\left(x_{0}\right)$ & 2.82 & 6.82 & 0.41 & -9.41 & 13.52 & 0.17 & 1.30 & 1970:II \\
\hline \multicolumn{9}{|l|}{ State variables } \\
\hline Real rate $\left(r_{t b}\right)$ & 1.26 & 1.28 & & -1.64 & 2.37 & 0.10 & 1.14 & 1952:II \\
\hline Dividend-price $(d p)$ & -3.46 & 0.40 & & -4.50 & -2.78 & -0.74 & 0.08 & 1952:II \\
\hline Nominal rate $\left(r_{\text {nom }}\right)$ & 5.01 & 1.36 & & 0.15 & 3.55 & 0.95 & 1.13 & 1952:II \\
\hline Term spread $(s p r)$ & 1.24 & 0.59 & & -0.71 & 0.98 & -0.10 & 0.36 & 1952:II \\
\hline Credit spread (cs) & 1.55 & 0.32 & & 0.08 & 0.86 & 0.37 & -0.39 & 1952:II \\
\hline
\end{tabular}

The table reports summary statistics over the entire sample for which a series is available. The starting quarter is given in the last column. The sample ends in 2005:IV. The average, standard deviation and Sharpe Ratio (SR) are annualized. The remaining statistics are on a quarterly basis. $X K$ is the excess kurtosis. The mean log returns are adjusted by one-half their variance so that they reflect mean gross returns.

Table 2

VAR of core variables: parameter estimates

\begin{tabular}{lcccccccc}
\hline & $r_{t b, t}$ & $x_{b, t}$ & $x_{s, t}$ & $d p_{t}$ & $r_{\text {nom }, t}$ & $s p r_{t}$ & $c s_{t}$ & $R^{2} / p$ \\
\hline$r_{t b, t+1}$ & 0.44 & 0.00 & 0.00 & -0.07 & 0.27 & 0.23 & -0.23 & 0.31 \\
& $(6.50)$ & $(0.18)$ & $(0.80)$ & $(0.70)$ & $(3.10)$ & $(1.37)$ & $(0.69)$ & $(0.00)$ \\
$x_{b, t+1}$ & 0.43 & -0.12 & -0.08 & -0.44 & 0.83 & 4.83 & -0.80 & 0.09 \\
& $(0.72)$ & $(1.39)$ & $(1.62)$ & $(0.47)$ & $(1.09)$ & $(3.29)$ & $(0.27)$ & $(0.01)$ \\
$x_{s, t+1}$ & 0.93 & 0.07 & 0.08 & 4.83 & -3.50 & -1.37 & 10.28 & 0.12 \\
& $(1.07)$ & $(0.62)$ & $(1.11)$ & $(3.56)$ & $(3.15)$ & $(0.64)$ & $(2.40)$ & $(0.00)$ \\
& -0.01 & -0.00 & -0.00 & 0.95 & 0.03 & 0.02 & -0.13 & 0.97 \\
$d p_{t+1}$ & $(1.64)$ & $(0.30)$ & $(0.69)$ & $(68.58)$ & $(3.01)$ & $(1.04)$ & $(3.06)$ & $(0.00)$ \\
& -0.04 & 0.01 & 0.00 & -0.02 & 1.03 & 0.20 & -0.43 & 0.90 \\
$r_{\text {nom }, t+1}$ & $(1.31)$ & $(1.90)$ & $(2.00)$ & $(0.41)$ & $(28.84)$ & $(2.88)$ & $(3.09)$ & $(0.00)$ \\
& 0.02 & -0.01 & -0.00 & 0.03 & -0.06 & 0.69 & 0.51 & 0.69 \\
$s p r_{t+1}$ & $(1.08)$ & $(2.00)$ & $(1.27)$ & $(1.01)$ & $(2.38)$ & $(13.17)$ & $(4.85)$ & $(0.00)$ \\
& -0.01 & -0.00 & -0.00 & -0.03 & 0.05 & 0.05 & 0.79 & 0.79 \\
$c s_{t+1}$ & $(0.77)$ & $(1.92)$ & $(2.23)$ & $(2.31)$ & $(4.04)$ & $(2.38)$ & $(17.34)$ & $(0.00)$ \\
& & & & & & & &
\end{tabular}

The table reports parameter estimates of the VAR $y_{t+1}=a+B y_{t}+\varepsilon_{t+1}$ with variables: 3-month T-bill, 20-year bonds, stocks, dividend yield, nominal 3-month T-bill, yield spread, and credit spread. T-statistics are reported in parenthesis. The last column contains the $R^{2}$ and the $p$-value of the F-statistic of joint significance. 
Table 3

VAR of core variables: error correlation matrix

\begin{tabular}{lrrlllll}
\hline & \multicolumn{1}{c}{$r_{t b}$} & \multicolumn{1}{c}{$x_{b}$} & \multicolumn{1}{c}{$x_{s}$} & $d p$ & $r_{\text {nom }}$ & $s p r$ & $c s$ \\
\hline$r_{t b}$ & 0.53 & \multicolumn{1}{c}{-} & - & - & - & - & - \\
$x_{b}$ & 0.37 & 4.64 & - & - & - & - & - \\
$x_{s}$ & 0.23 & 0.12 & 6.76 & - & - & - & - \\
$d p$ & -0.26 & -0.13 & -0.98 & 0.07 & - & - & - \\
$r_{\text {nom }}$ & -0.36 & -0.63 & -0.06 & 0.07 & 0.22 & - & - \\
$s p r$ & 0.21 & 0.12 & -0.01 & 0.01 & -0.82 & 0.17 & - \\
$c s$ & 0.07 & 0.57 & -0.16 & 0.14 & -0.28 & -0.12 & 0.07 \\
\hline
\end{tabular}

The table reports the error covariance matrix $\Sigma_{\varepsilon \varepsilon}$ of the VAR $y_{t+1}=a+B y_{t}+\varepsilon_{t+1}$ with variables: 3month T-bill, 20-years bonds, stocks, dividend yield, nominal 3-month T-bill, yield spread, and credit spread. Diagonal entries are standard deviations; off-diagonal entries are correlations.

on contemporaneous stock returns. The significant positive coefficients, however, predict that next period stock returns rise. In this way, both the credit spread and the dividend-price ratio imply mean reversion in stocks returns.

The yield spread is a strong predictor for bond returns. Although less significant, the nominal interest rate and stock returns also capture some dynamics in expected bond returns. The nominal interest rate is a mean-reversion mechanism in bond returns, whereas the covariance structure of the term spread leads to a mean aversion component. The $R^{2}$ of $9 \%$ implies that bond returns are difficult to explain, even more difficult than stocks which have an $R^{2}$ of $12 \%$. Yet, Campbell and Thompson (2008) show that even a small $R^{2}$ can be economically meaningful.

Dynamics of the state variables are consistent with earlier results. The coefficients of both the nominal interest rate (1.03) and the dividend-price ratio $(0.95)$ on their own lags indicate that these series are very persistent. The maximal eigenvalue of the coefficient matrix equals 0.977 . The system is stable, but close to being integrated of order one. Although the credit spread is less persistent than the dividend-price ratio, its autocorrelation coefficient (0.79) is higher than that of the yield spread $(0.69)$. Both nominal interest rate and credit spread have a significant explanatory power for all four macro-economic state variables.

The system (18) and (19) imposes restrictions on the VAR parameters $\boldsymbol{\Phi}_{1}$. These restrictions can be tested for the subsample where all data series are available (1990:II-2005:IV). We tested the exclusion restriction on $x_{2}$ in the core VAR and could not reject the null hypothesis of absence of Granger causality $(p=0.24)$.

Table 4 shows the estimation results for the returns in $x_{2}$. Credits are well explained by stocks and bonds, its own lagged return, and news about the credit spread and the change in the long yield. Credit returns decrease when yields rise or credit spreads widen. The results are consistent with the notion that corporate bonds are a hybrid between default-free bonds and the firm's equity. According to De Jong and Driessen (2008) corporate bonds are related both to government bonds and stocks because of liquidity shocks in both markets. 
Table 4

Excess return regressions

\begin{tabular}{|c|c|c|c|c|c|c|c|c|c|c|}
\hline & \multicolumn{6}{|c|}{ Contemporaneous } & \multicolumn{4}{|c|}{ Lagged } \\
\hline & $r_{t b, t+1}$ & $x_{b, t+1}$ & $x_{s, t+1}$ & $s p r_{t+1}$ & $\Delta y_{t+1}^{10}$ & $\Delta c s_{t+1}$ & $r_{t b, t}$ & $x_{b, t}$ & $o w n_{t}$ & $R^{2} / p$ \\
\hline \multirow[t]{2}{*}{$x_{\mathrm{cr}, t+1}$} & - & 0.40 & 0.04 & - & -20.50 & -10.43 & - & 0.10 & -0.15 & 0.90 \\
\hline & - & $(6.52)$ & $(2.94)$ & - & $(8.16)$ & $(5.88)$ & - & $(1.90)$ & $(2.60)$ & 0.10 \\
\hline \multirow[t]{2}{*}{$x_{\mathrm{cm}, t+1}$} & -4.55 & - & -0.23 & - & - & - & 2.62 & - & - & 0.14 \\
\hline & $(3.59)$ & - & $(2.33)$ & - & - & - & $(2.09)$ & - & - & 0.45 \\
\hline \multirow[t]{2}{*}{$x_{\mathrm{re}, t+1}$} & - & 0.32 & 0.65 & 4.48 & - & - & - & - & - & 0.49 \\
\hline & - & $(3.35)$ & $(9.27)$ & $(2.80)$ & - & - & - & - & - & 0.47 \\
\hline \multirow[t]{2}{*}{$x_{h, t+1}$} & - & - & 0.19 & - & - & - & - & - & - & 0.22 \\
\hline & - & - & $(4.09)$ & - & - & - & - & - & - & 0.87 \\
\hline \multirow[t]{2}{*}{$x_{0, t+1}$} & -1.97 & 0.19 & -0.07 & - & -15.86 & -3.89 & - & - & -0.12 & 0.78 \\
\hline & $(9.48)$ & $(2.22)$ & $(3.23)$ & - & (4.79) & (1.83) & - & - & $(2.37)$ & 0.27 \\
\hline
\end{tabular}

The table reports parameter estimates for the excess returns of the assets in the subset $x_{2}$ : credits $\left(x_{\mathrm{cr}}\right)$, commodities $\left(x_{\mathrm{cm}}\right)$, listed real estate $\left(x_{\mathrm{re}}\right)$, hedge funds $\left(x_{h}\right)$ and liabilities $\left(x_{L}\right)$. For each asset we report the regression results after setting to zero all insignificant coefficients in the general specification

$$
x_{2, t+1}=c+D_{0} y_{t+1}+D_{1} y_{t}+H x_{2, t}+\eta_{t+1}
$$

and after reparameterization. Reparameterization involves the first differences of the variables $y^{10}=$ $s p r+r_{\text {nom }}$ and $c s$. Explanatory variables in $y_{t}$ are the nominal T-bill rate $\left(r_{\text {nom }}\right)$, the term spread $(s p r)$, the default spread $(c s)$, and the dividend-price ratio $(d p)$. The last column reports the regression $R^{2}$ and the $p$ value of the F-statistic of the zero restrictions with respect to the general model.

The primary assets can hardly explain commodity returns. Commodities have as much predictability as stocks and bonds $\left(R^{2}=0.14\right)$; the negative exposure to stocks confirms the findings of Gorton and Rouwenhorst (2006) that stocks and commodities behave differently across the business cycle. Returns are negatively related to an increase in the real T-bill because it leads to a loss on cash collateral. The real estate series are rather well explained $\left(R^{2}=49 \%\right)$ by contemporaneous bonds, stocks and term spreads. Hedge funds are only explained by their equity exposure $\left(R^{2}=22 \%\right)$. Finally, liabilities are mainly driven by real T-bills, bonds and the change in the long yield. The coefficient on the change in the long yield reflects the high duration of liabilities.

\section{Term structures of assets and liabilities}

This section discusses the term structure of risk implied by the VAR model. ${ }^{9}$ We discuss the results in four subsections. We first look at the volatilities. Next we consider all covariances with stocks, bonds, inflation and liabilities.

\footnotetext{
${ }^{9}$ See Campbell and Viceira (2005b) for a technical derivation of the term structure in terms of VAR parameters.
} 


\subsection{Term structure of risk}

We start with the time diversification properties within an asset class. Fig. 1 shows the annualized conditional standard deviation of cumulative real holding period returns of all asset classes for investment horizons up to 25 years. The relevant term structures for an asset-only and an asset-liability investor are different. The assetonly investor considers real returns, whereas the asset-liability investor is concerned with returns in excess of the return on the liabilities.

Results for stocks, bonds and T-bills confirm findings in Campbell and Viceira (2005a). Stocks are less risky in the long run: volatility drops from $14 \%$ in the first quarter to $10.5 \%$ after 10 years and $8 \%$ after 25 years. The mean reverting behavior of stock returns is normally attributed to the dividend yield. In our model this effect is reinforced by the credit spread. Both variables have a positive impact on expected future returns. In a present value model, an increase in the discount rate for future cashflows lowers the value of an asset. When cashflows do not increase as much, the
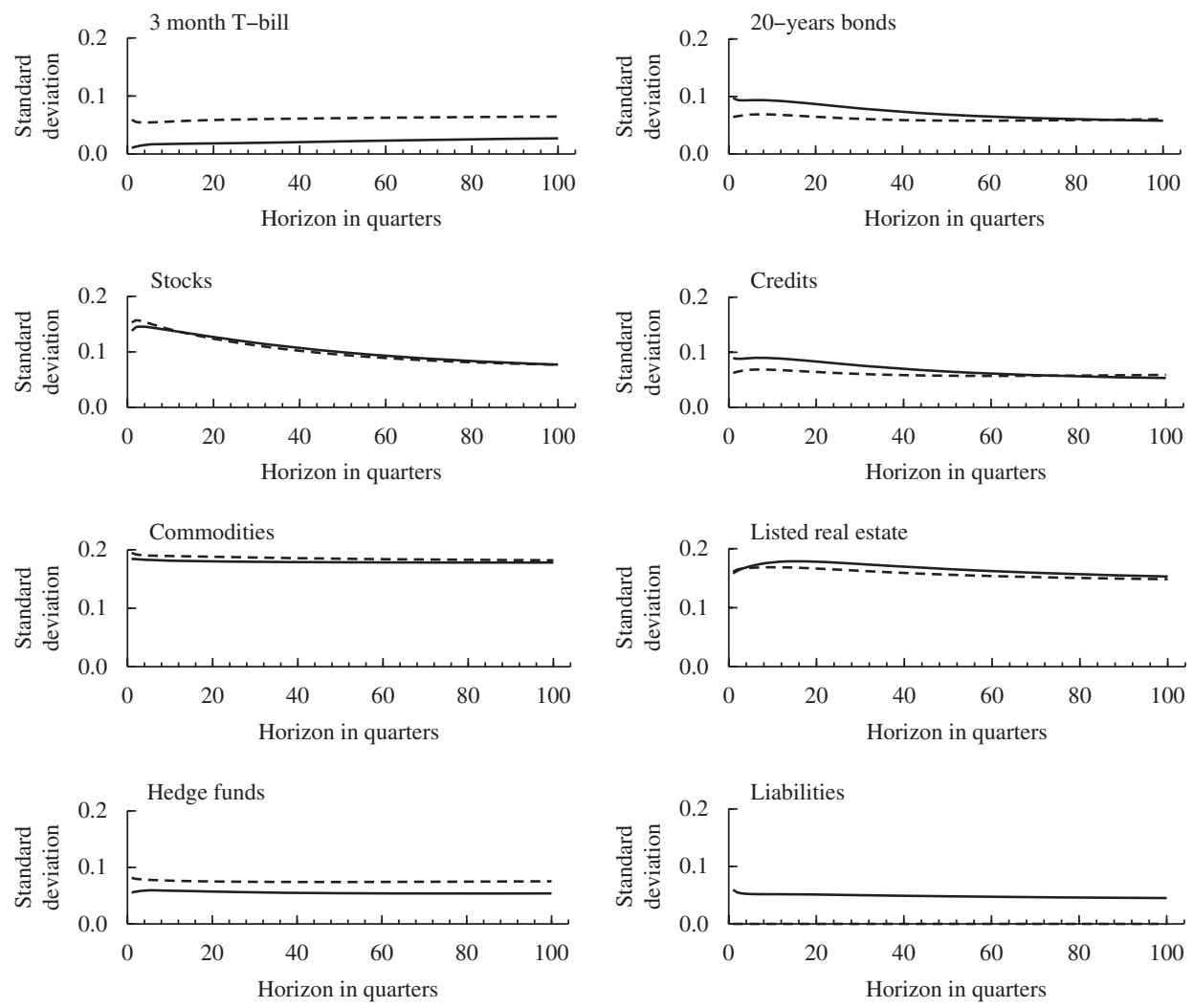

Fig. 1. Time diversification. Annualized volatilities ( $y$-axis) across different investment horizons (in quarters on $x$-axis). Solid lines represent real asset returns. Dashed lines represent real asset returns relative to the liabilities. 
stock price has to fall to accommodate the higher expected returns. Empirically Campbell and Vuolteenaho (2004) find that the discount rate effect dominates the cashflow effect. Hence increased future expected returns are negatively correlated with current returns.

Returns on a constant 20-year maturity rolling bond portfolio also exhibit mean reversion, but less so because of two offsetting effects. A negative shock in the short rate induces a positive shock in bond returns, and subsequently predicts that nextperiod bond returns will decrease. In contrast, shocks in the term spread variable are positively correlated with both current and future bond returns. As the short rate is more persistent than the spread, the mean reverting effect of the short rate dominates. Risks of a constant 20 -year maturity bond portfolio decline from $10 \%$ after one quarter to $6 \%$ after 25 years.

The 90-day T-bill is more risky in the long run due to the reinvestment risk inherent in persistent variation of real interest rates. At longer investment horizons the risk of reinvesting in the 90-day T-bill approaches the risk of a rolling investment in 20 year bonds. We also observe persistence in the inflation process, meaning that inflation is a long-term risk factor.

Time diversification in credit returns is partially related to the credit spread. Credits also inherit some of the mean reversion of bonds due to the strong correlation between the two returns. Coefficient estimates of the VAR are significant and positive, while shocks are negatively correlated. Credit returns decline when credit spreads widen or bond yields rise. The volatility of credits is below that of bonds because of the negative correlation between changes in credit spreads and yields.

The term structure of listed real estate shows a hump-shaped pattern. For investment horizons up to four years listed real estate exhibits mean aversion due to persistency of interest rates which is captured in our model by the yield spread. Furthermore the drivers for mean reversion in stock and bond returns also influence the term structure of listed real estate. Mean reversion dominates in the long run. Nevertheless listed real estate exhibits less mean reversion than stocks and the term structure lies above the one of stocks.

Commodity returns do not exhibit time diversification. In the VAR they are explained by contemporaneous stock returns and real T-bill. With mean-reverting stocks returns and a rising term structure of T-bills the combined effect results in a flat term structure for commodities.

Hedge fund returns also have a flat term structure. At short horizons the term structure is affected by the unsmoothing filter applied to hedge fund returns. Without unsmoothing the term structure would be rising from a low level of volatility at short investment horizons.

Liability risk exhibits very limited horizon effects, because two effects offset each other. Liabilities are the sum of long-term real bond returns plus inflation. The real bond returns exhibit mean reversion, whereas inflation has a mean averting character. The total effect is a modestly downward-sloping term structure of risk.

Term structures relative to liabilities are markedly different for T-bills and bonds. For an asset-liability investor T-bills are about three times as risky as for an 
asset-only investor (5.4\% versus $1.6 \%$ for an annual horizon). The duration mismatch of T-bills makes them as risky as bonds. The risk of bonds and credits is substantially lower in the short and medium term when there are liabilities (the difference is $2.5 \%$ points for bonds for an annual horizon). In the long run, differences are smaller because cumulative inflation risk dominates the term structures. Since stocks, commodities and listed real estate have high stand-alone risk and a low correlation with liabilities, the term structures do not change greatly relative to liabilities.

\subsection{Risk diversification}

To examine the diversification possibilities between asset classes at different horizons we look at the correlations of real returns on stocks and bonds with other asset classes in Fig. 2.

The correlation between stocks and bonds changes drastically along the investment horizon. The correlation is lowest in the very short run (around 25\%) and in the long run (47\% for a 25 -year horizon). For investors with a medium-term investment horizon, risk diversification possibilities are worse since the correlation can be up to $64 \%$. As stock prices react more slowly to changes in the interest rate than bond returns, the correlation increases in the medium term. If interest rates increase, bond returns immediately decline (the correlation between the innovations is -0.63 ), whereas it has a smaller effect on contemporaneous stock returns (the correlation between the innovations is -0.06$)$. However, the coefficient of interest rates on next period stock returns $(-3.50)$ implies that the majority of the decrease will occur in the next periods.

The correlation between stocks and credits is similar to the correlation between stocks and bonds. An explanation is that credit returns vary systematically with the same factors that affect stock returns (see Elton et al., 2001). Default loss moves with equity prices. If stock prices decline, default risk goes up and vice versa. Furthermore, the compensation for risk required in the market changes over time and affects stocks and corporate bonds in the same way. Obviously bonds are highly correlated with credits at all horizons with a correlation that is always more than $90 \%$.

T-bills are a good diversifier in a portfolio with stocks or long-term bonds. The correlation of bonds with the T-bill has a U-shape. It starts high for short horizons at $45 \%$, comes down to $8 \%$ for the medium term and rises again to $22 \%$ at longer horizons. The low correlation is due to duration mismatch. Returns on T-bills rise rather quickly when interest rates rise, whereas bonds with a longer maturity are more sensitive to interest rate changes. The correlation between stocks and the T-bill is high for short horizons $(45 \%)$ but this comes down to $-10 \%$ after 25 years.

Listed real estate is often seen as similar to equity. The correlation $(65 \%)$ is high at short investment horizons, but diminishes with the investment horizon. Indirect real estate indices are based on publicly traded property companies listed on major stock exchanges. Froot (1995) explains that similar factors (e.g. productivity of capital and labor) drive both stocks and real estate and that lots of corporate assets are invested 

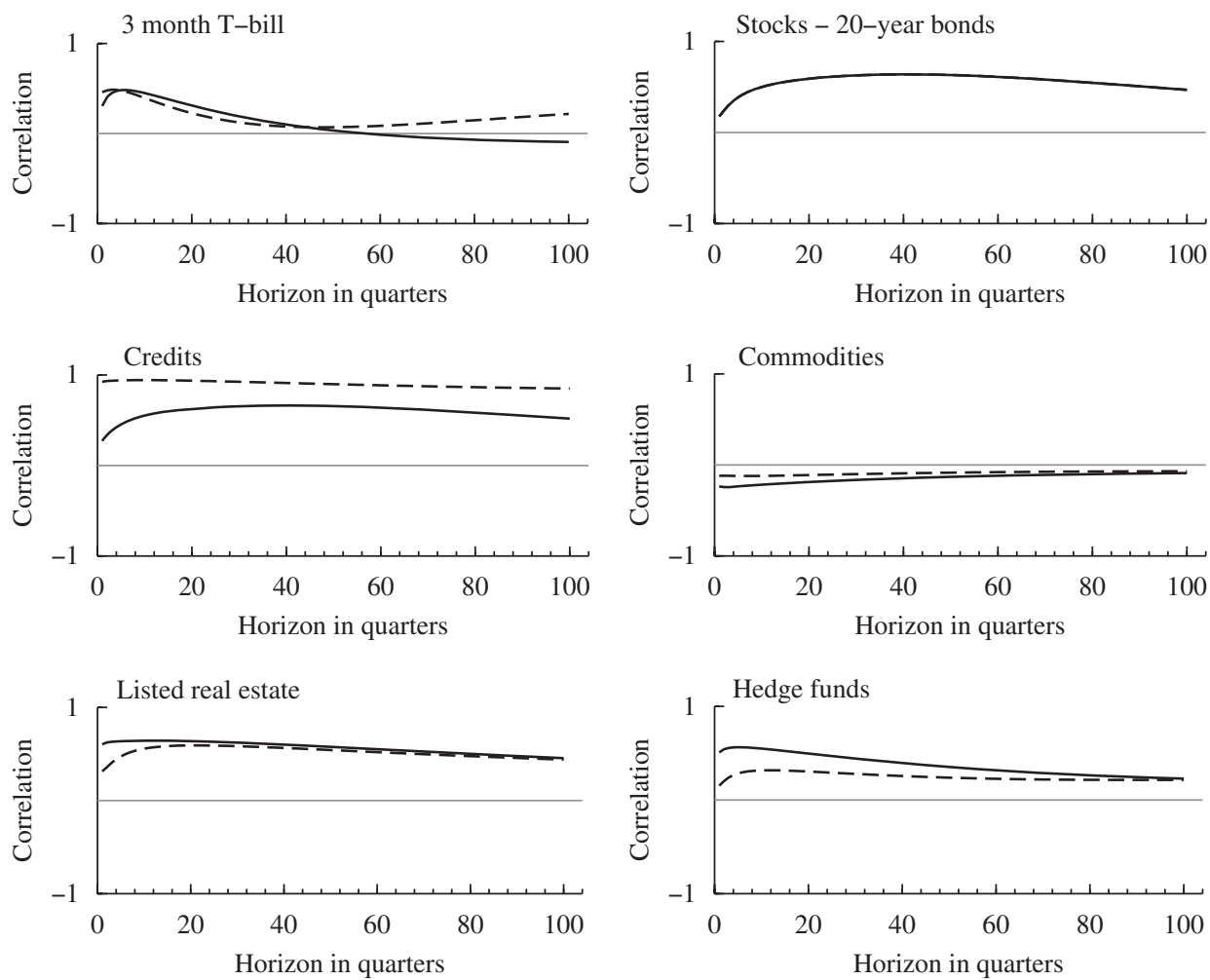

Fig. 2. Correlations with stocks and bonds. Correlations of real stock returns (solid lines) and real bond returns (dashed lines) with other real asset returns ( $y$-axis) across different investment horizons (in quarters on $x$-axis).

in real estate. As a consequence listed indices tend to have a high correlation with publicly traded stocks and bonds indices. In this sense real estate does not seem like a very different asset class. ${ }^{10}$

Horizon effects in the correlation between stocks and hedge funds follow from the return dynamics in Table 4. Excess hedge fund returns are driven by excess stock returns and market-unrelated risks. In the short run, the correlation is driven by the equity exposure, whereas the market-unrelated risks start dominating in the long run. As a result, the correlation moves from $56 \%$ for short horizons towards $23 \%$ in the long run. The magnitude of the short-term correlation implies a relatively large exposure to the stock market which reduces in the long run. Bond exposure is less than equity exposure and has a lagged effect. Like the correlation between stocks and bonds, the correlation between hedge funds and bonds initially increases with the investment horizon before decreasing for horizons beyond three years.

\footnotetext{
${ }^{10}$ The conclusion might be different for direct real estate. Since direct real estate is not listed on publicly traded financial markets, this could imply lower correlations with stocks and bonds.
} 
Since commodities are negatively correlated with both stocks and bonds at all horizons they have the best diversification properties. Commodity returns behave differently, since unlike stocks and bonds, commodities are not claims on long-lived corporations and they do not provide resources for firms to invest. Rather commodity futures are derivatives and provide insurance for future values of inputs or outputs. Gorton and Rouwenhorst (2006) explain the negative correlations in two ways. First, commodities perform better in periods of unexpected inflation when stocks and bonds disappoint. Second, commodities behave differently over the business cycle. Commodity futures perform well in the early stages of a recession, because generally speaking oil and energy-related prices increase. Stocks and bonds generally disappoint in the early stages of a recession. In late stages of a recession, returns are the other way round.

\subsection{Inflation hedging qualities}

This section examines the potential of stocks, bonds and the alternatives as a hedge against inflation for different investment horizons. Since inflation is not explicitly included in the VAR, we construct its properties from the difference between the real $\mathrm{T}$-bill return and the lagged nominal interest rate (i.e. $\pi_{t}=$ $\left.r_{\text {nom, } t-1}-r_{t b, t}\right)$. Fig. 3 shows the correlation of nominal asset returns with inflation across investment horizons. The correlation with inflation changes substantially with the horizon for all asset classes. All asset classes are a better hedge against inflation in the long run than in the short run. There are, however, marked differences among asset classes.

The T-bill quickly catches up with inflation changes, and therefore seems the best inflation hedge at all horizons. The high correlation with inflation is due to rolling over 3-months T-bills, which ensures that the lagged inflation is incorporated.

Inflation-hedging qualities of bonds and credits are good in the long run, but poor in the short run due to the inverse relationship between yield changes and bond prices. The positive long-term correlations are mainly due to the use of constantmaturity bonds, whereas Campbell and Viceira (2005a) show that holding bonds to maturity is akin to accumulating inflation risk. The negative short-term hedging qualities of credits are also related to the negative relationships between inflation and real economic growth. The credit spread widens in business cycles downturns, which leads to a negative return.

Stocks also turn out to be a good inflation hedge in the long run and a poor one in the short run, consistent with the extensive existing literature on this relation (see for instance Schotman and Schweitzer, 2000). Fama (1981) argues that inflation, acting as a proxy for real activity, leads to the negative short-term correlation. Increasing inflation would lead to lower real economic activity and this leads to lower stock returns. In particular, unexpected inflation is related to negative output shocks, which generally lead to falling stock prices. The positive inflation hedge potential in the long run could be explained by a present-value calculation of real stock prices. Campbell and Shiller (1988) distinguish two offsetting effects. First, inflation increases the discount rate, which lowers stock prices. Second, inflation increases future dividends, 

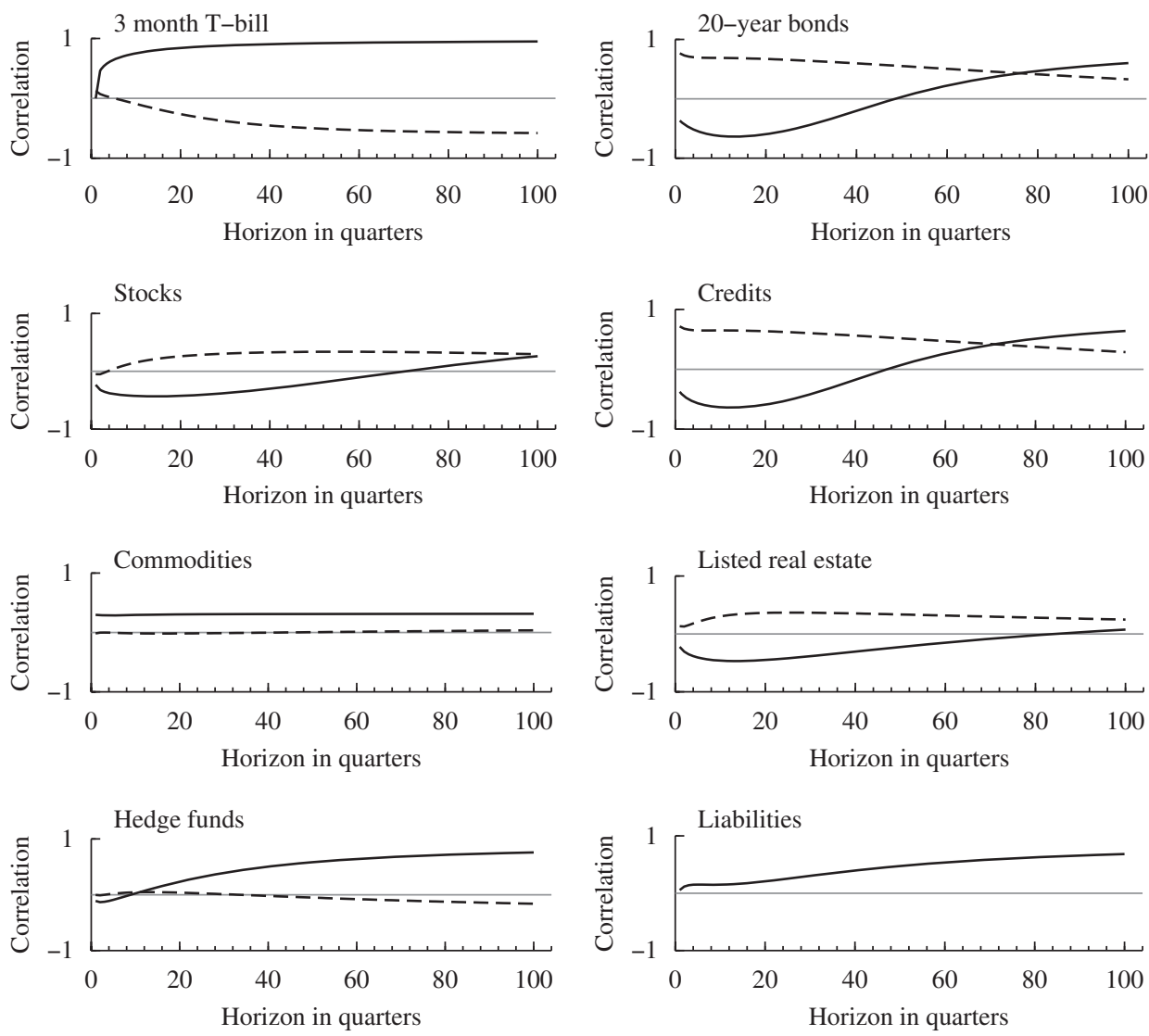

Fig. 3. Inflation hedge and real interest rate hedge properties. Solid lines represent correlations between inflation and nominal asset returns. Dashed lines represent correlations between real returns on liabilities and real asset returns. Correlations are on the $y$-axis across different investment horizons (in quarters on $x$-axis).

which boosts stock prices. They argue that due to price rigidities in the short run, the net effect will be negative in the short run, but positive in the long run.

Commodity prices move along with inflation in the short and the long term, which makes them very attractive from an inflation hedge perspective. Bodie (1983) shows that the risk-return trade-off of a portfolio in an inflationary environment can be improved by the addition of commodity futures to a portfolio consisting of stocks and bonds. Gorton and Rouwenhorst (2006) argue that as futures prices include information about expected trends in commodity prices, they rise and fall with unexpected inflation. We find commodity futures have very stable inflation hedging qualities.

Listed real estate behaves like stocks in the short run from an inflation hedge perspective, although stocks are a slightly better inflation hedge in the long run. This is again in line with the observation that listed real estate behaves like stocks. 
Hedge funds are better inflation hedges in the short run than most assets, but they still have a negative inflation hedge potential. As hedge fund returns are often seen as Libor plus an alpha component, the long-term inflation hedging qualities may come from the Libor part of the return which moves with the lagged inflation.

\subsection{Real interest rate hedging qualities}

The liabilities of pension funds are the present value of future obligations, discounted at a real interest rate. This section therefore studies the potential of stocks, bonds and alternatives (in real terms) as a hedge against real interest rate risk at different investment horizons.

Fig. 3 shows that the real interest rate hedge potential of the asset classes change substantially with the investment horizon. Bonds and credits provide the best real interest rate hedge. Bonds have a correlation of around $70 \%$ at an annual investment horizon. Due to cumulative inflation, the correlation reduces to $35 \%$ in the long run. The hedging qualities of credits are slightly lower owing to the lower duration and the credit exposure. The mismatch between the quarterly inflation compensation of the liabilities and the expected long-term inflation implicitly in the long yields underlying the investment strategies becomes more severe at longer horizons. As a consequence, cumulative unexpected inflation shocks lead to a reduction of liability hedging potential along the investment horizon.

The real interest rate hedge qualities of stocks and listed real estate are comparable, although the latter provides a slightly better hedge due to the exposure to spreads and bonds. Both term structures are hump-shaped. In the short run the correlation of listed real estate is around $14 \%$; it reaches a maximum at the seven year horizon with a correlation of $37 \%$; it then falls to $25 \%$ at a 25 year horizon. The correlation between stocks and the real interest rate reaches its maximum of $34 \%$ at around 15 years.

Commodities and hedge funds show very low correlations with the liabilities across all horizons. T-bills have the worst liability hedging qualities among the assets in our universe. Apart from duration mismatch with long-dated liabilities, cumulative unexpected inflation risk leads to a declining correlation. The correlation between real T-bills and liabilities converges to $-57 \%$ in the long run. Combining the inflation and the real interest rate hedging qualities of T-bills and long-dated bonds (in Fig. 3) reveals pitfalls of nominal swap-overlay strategies which are often considered by asset-liability investors for liability matching by duration extension. The long receiver rate is a better liability hedge, while the short payer rate exposes the investor to substantial inflation risk.

\section{Strategic asset-liability management}

We now turn to the portfolio implications. We compare the optimal meanvariance portfolio for the asset-liability investor in (11) with the asset-only portfolio (17). Differences in strategic asset allocation are due to the GMV and the LHPs. 
We discuss these portfolios for investment horizons of $1,5,10$ and 25 years in Section 5.1. In Section 5.2 we add the speculative portfolio for risk aversion parameters $\gamma=5$ and 20 .

\subsection{Hedge portfolios}

Table 5 shows the GMV and LHP portfolios at different investment horizons. At the 1-year horizon the GMV portfolio is entirely invested in T-bills, exactly as in Campbell and Viceira (2005a). At longer horizons much of the weight shifts to longterm bonds and stocks. At the 25-year horizon, 6\% of the GMV consists of alternatives. If we compare the hedge portfolios with portfolios which are restricted to T-bills, bonds and stocks only, we find that the alternatives drive bonds and T-bills out of the hedge portfolio in favor of credits and commodities.

The LHP is very different. At the 1-year horizon, the weight of T-bills is much lower than in the GMV. The asset-liability investor chooses primarily bonds $(34 \%)$ and credits $(12 \%)$. Bonds are the best hedge against real interest rate risk, and therefore have a large weight in the LHP. Credits have a substantial weight $(12-21 \%)$ in the LHP, because they are the second-best real rate hedge. They replace bonds to some degree, as they offer some risk diversification benefits, despite their somewhat lower hedge potential. Even though T-bills $(62 \%)$ are a bad liability hedge, they still have a substantial allocation in the portfolio. T-bills remain attractive for their low risks at short horizons. At longer horizons they are in the portfolio for their diversification properties with stocks and bonds and for their good

Table 5

Global minimum variance and liability hedge portfolios

\begin{tabular}{|c|c|c|c|c|c|c|c|c|}
\hline \multirow[t]{2}{*}{ Horizon (years) } & \multicolumn{4}{|c|}{ Global minimum variance } & \multicolumn{4}{|c|}{ Liability hedge } \\
\hline & 1 & 5 & 10 & 25 & 1 & 5 & 10 & 25 \\
\hline \multicolumn{9}{|c|}{ (A) Unrestricted portfolios } \\
\hline T-bills $\left(r_{t b}\right)$ & 1.06 & 0.99 & 0.92 & 0.83 & 0.62 & 0.52 & 0.41 & 0.29 \\
\hline Bonds $\left(x_{b}\right)$ & -0.01 & 0.03 & 0.04 & 0.01 & 0.34 & 0.39 & 0.38 & 0.28 \\
\hline Stocks $\left(x_{s}\right)$ & -0.03 & -0.03 & -0.01 & 0.12 & -0.11 & -0.11 & -0.06 & 0.20 \\
\hline Credits $\left(x_{\mathrm{cr}}\right)$ & -0.03 & -0.02 & 0.01 & 0.01 & 0.12 & 0.16 & 0.21 & 0.16 \\
\hline Commodities $\left(x_{\mathrm{cm}}\right)$ & 0.02 & 0.02 & 0.02 & 0.04 & 0.03 & 0.04 & 0.04 & 0.06 \\
\hline Real estate $\left(x_{\mathrm{re}}\right)$ & 0.00 & 0.01 & 0.01 & 0.01 & 0.00 & 0.01 & 0.01 & 0.01 \\
\hline Hedge funds $\left(x_{h}\right)$ & 0.00 & 0.00 & 0.00 & 0.00 & 0.00 & 0.00 & 0.00 & 0.00 \\
\hline \multicolumn{9}{|c|}{ (B) Restricted portfolios } \\
\hline T-bills $\left(r_{t b}\right)$ & 1.08 & 1.01 & 0.94 & 0.86 & 0.67 & 0.57 & 0.48 & 0.37 \\
\hline Bonds $\left(x_{b}\right)$ & -0.05 & 0.02 & 0.06 & 0.01 & 0.44 & 0.53 & 0.56 & 0.39 \\
\hline Stocks $\left(x_{s}\right)$ & -0.03 & -0.03 & -0.01 & 0.13 & -0.11 & -0.10 & -0.04 & 0.23 \\
\hline
\end{tabular}

The left panel shows the global minimum variance portfolio for the asset-only problem for different investment horizons. The right panel shows the liability hedge portfolio for the asset-liability problem. Weights may not add up to one due to rounding. Panel A considers the full menu of all seven asset classes. Panel B excludes the alternatives. 
inflation hedging qualities. At short horizons stocks are less attractive due to their limited hedging qualities. At the 25 years horizon, however, stocks obtain more weight in the LHP than in the GMV.

At a 25 -year horizon, $23 \%$ of the LHP is allocated to the alternative assets. Most of the weight comes from the credits. Commodities also have a positive weight simply because they are a good risk diversifier to the other asset classes and a good inflation hedge. Moreover, their weight increases with the investment horizon. The LHP allocates $1 \%$ to listed real estate and does not include hedge funds.

From the allocation to T-bills, long bonds and credits we calculate that the duration of the fixed-income portfolio in the LHP is around 8 years, which is below the 17 years duration assumed for the liabilities. The duration gap occurs for several reasons. First, short-term instruments offer diversification in a portfolio of long-term bonds (see also Brennan and Xia, 2002). Furthermore, long-term bonds are a better long real rate hedge, whereas short-term bonds provide a better hedge against cumulative inflation. Finally, stocks also have positive real rate hedging qualities at longer horizons. As a result of the intertemporal covariance structure the duration of the fixed-income portfolio is horizon dependent. It rises from 7 for a 1-year horizon to 9 for a 25 -year horizon.

\subsection{Do alternative asset classes add value for long-term investors?}

In this section we investigate the role of alternatives when the investor deviates from the LHP or GMV portfolios. For the expected returns we use the unconditional full sample means. In Table 6 we show the strategic asset allocation for an asset-liability and an asset-only investor for different degrees of risk aversion.

An asset-liability investor with a 1-year horizon holds a well-diversified portfolio. Hedge funds are in the optimal portfolio for their return enhancement qualities, at the expense of stocks and real estate. Bonds and credits are in the portfolio for their liability-hedging qualities and their low correlation with all other assets. Credits are a substitute for bonds for investors with lower risk aversion. Commodities are particularly interesting as a risk diversifier. Combined with the high Sharpe ratio of commodities, this explains the substantial positive weighting of this asset class. When risk aversion increases, the portfolio contains more bonds and T-bills, and less of the other asset classes.

The mean reverting character of stocks results in increasing weights at longer horizons. In addition, credits replace bonds to some extent. The flat term structure of commodities explains why their portfolio weight is stable over the investment horizon. Listed real estate does not seem to add much, neither in relation to liability hedging nor to risk diversification. The allocation to hedge funds exhibits even less horizon effects than commodities and real estate. Their weight only changes due to changes in risk attitude.

What is the added value of alternatives and credits? And what are the benefits of explicitly taking an asset-liability perspective? Is it associated with expected returns, risk diversification or liability-hedge potential? To answer these questions we calculate the certainty equivalent costs of three alternative portfolios. 
Table 6

Optimal portfolio choice

\begin{tabular}{|c|c|c|c|c|c|c|c|c|c|}
\hline \multirow[t]{2}{*}{$\gamma$} & \multirow[t]{2}{*}{ Horizon (years) } & \multicolumn{4}{|c|}{ Asset-only } & \multicolumn{4}{|c|}{ Asset-liability } \\
\hline & & 1 & 5 & 10 & 25 & 1 & 5 & 10 & 25 \\
\hline \multirow{8}{*}{5} & (A) Unrestricted por & olios & & & & & & & \\
\hline & T-bills $\left(r_{t b}\right)$ & -1.27 & -1.11 & -1.18 & -1.64 & -1.61 & -1.48 & -1.56 & -2.00 \\
\hline & Bonds $\left(x_{b}\right)$ & -0.08 & -0.42 & -0.51 & -0.30 & 0.17 & -0.19 & -0.30 & -0.13 \\
\hline & Stocks $\left(x_{s}\right)$ & 0.65 & 0.90 & 1.14 & 1.42 & 0.58 & 0.87 & 1.15 & 1.50 \\
\hline & Credits $\left(x_{\mathrm{cr}}\right)$ & 0.27 & 0.27 & 0.24 & 0.24 & 0.40 & 0.41 & 0.36 & 0.30 \\
\hline & Commodities $\left(x_{\mathrm{cm}}\right)$ & 0.61 & 0.59 & 0.57 & 0.52 & 0.62 & 0.61 & 0.59 & 0.55 \\
\hline & Real estate $\left(x_{\mathrm{re}}\right)$ & 0.06 & 0.00 & -0.02 & 0.00 & 0.06 & 0.02 & 0.00 & 0.01 \\
\hline & Hedge funds $\left(x_{h}\right)$ & 0.76 & 0.76 & 0.76 & 0.76 & 0.76 & 0.76 & 0.76 & 0.76 \\
\hline \multirow[t]{8}{*}{20} & T-bills $\left(r_{t b}\right)$ & 0.49 & 0.49 & 0.43 & 0.23 & 0.07 & 0.04 & -0.04 & -0.25 \\
\hline & Bonds $\left(x_{b}\right)$ & -0.04 & -0.13 & -0.18 & -0.14 & 0.29 & 0.19 & 0.11 & 0.10 \\
\hline & Stocks $\left(x_{S}\right)$ & 0.14 & 0.23 & 0.35 & 0.56 & 0.06 & 0.17 & 0.32 & 0.64 \\
\hline & Credits $\left(x_{\mathrm{cr}}\right)$ & 0.04 & 0.06 & 0.05 & 0.02 & 0.20 & 0.22 & 0.22 & 0.14 \\
\hline & Commodities $\left(x_{\mathrm{cm}}\right)$ & 0.17 & 0.16 & 0.16 & 0.15 & 0.18 & 0.18 & 0.18 & 0.18 \\
\hline & Real estate $\left(x_{\mathrm{re}}\right)$ & 0.01 & 0.01 & 0.00 & 0.00 & 0.01 & 0.02 & 0.01 & 0.01 \\
\hline & Hedge funds $\left(x_{h}\right)$ & 0.19 & 0.19 & 0.19 & 0.19 & 0.19 & 0.19 & 0.19 & 0.19 \\
\hline & (B) Restricted portf & & & & & & & & \\
\hline \multirow[t]{3}{*}{5} & T-bills $\left(r_{t b}\right)$ & 0.26 & 0.31 & 0.16 & -0.41 & -0.05 & -0.03 & -0.19 & -0.73 \\
\hline & Bonds $\left(x_{b}\right)$ & 0.09 & -0.20 & -0.31 & -0.12 & 0.46 & 0.16 & 0.01 & 0.11 \\
\hline & Stocks $\left(x_{s}\right)$ & 0.65 & 0.89 & 1.15 & 1.53 & 0.59 & 0.88 & 1.18 & 1.62 \\
\hline \multirow[t]{3}{*}{20} & T-bills $\left(r_{t b}\right)$ & 0.88 & 0.85 & 0.77 & 0.53 & 0.50 & 0.44 & 0.34 & 0.10 \\
\hline & Bonds $\left(x_{b}\right)$ & -0.02 & -0.07 & -0.12 & -0.12 & 0.44 & 0.39 & 0.32 & 0.21 \\
\hline & Stocks $\left(x_{s}\right)$ & 0.13 & 0.22 & 0.35 & 0.59 & 0.06 & 0.17 & 0.34 & 0.69 \\
\hline
\end{tabular}

The table shows the fixed-weights optimal portfolio holdings for two types of investor (asset-only versus asset-liability) who plan to invest constant proportions of wealth in each of the asset classes for four investment horizons $(1,5,10$, and 25 years) and for two levels of risk aversion $(\gamma=5,20)$. Panel A considers the full menu of all seven asset classes. Panel B excludes the alternatives. Weights may not add up to one due to rounding.

First we consider an investor who is restricted to T-bills, bonds and stocks. The alternatives drive T-bills and bonds further out of the portfolio in favor of the alternatives with higher expected returns like hedge funds, commodities and credits. Panel (a) in Fig. 4 indicates that the alternative asset classes add value for long-term investors. At the 1-year horizon a risk averse $(\gamma=20)$ asset-liability investor requires a lump sum of 1.2 dollars for each 100 dollars of initial investment to be compensated for ignoring the four alternative asset classes. The cost can be attributed to three components. The largest component is the considerable expected return advantage from alternatives. Alternatives are thus not solely interesting for their liability hedging qualities. The liability hedge potential also contributes positively to the certainty equivalence cost. Alternatives have good liability hedge properties at all investment horizons and these become more important for longterm investing. The third component is negative: the variance of the unrestricted 


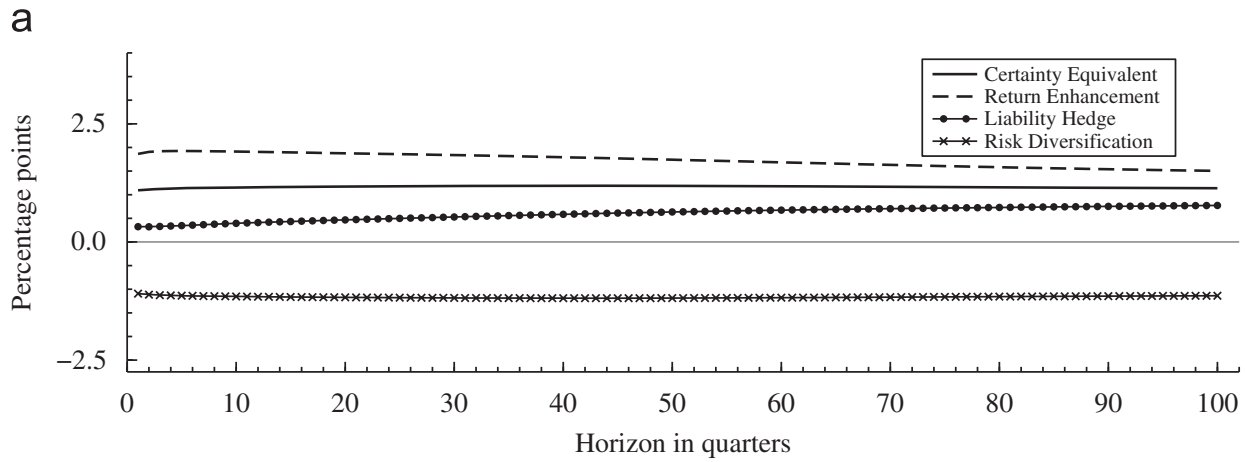

b

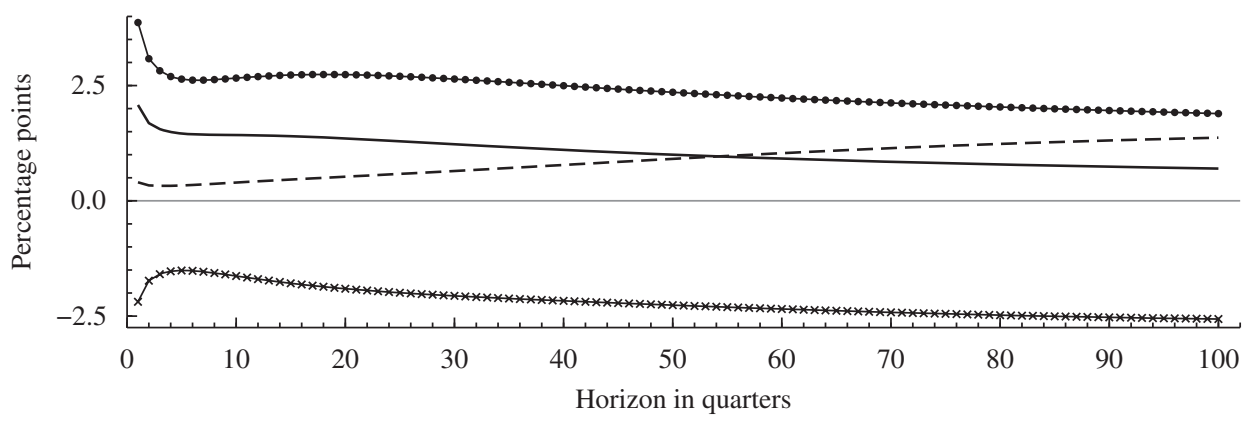

Fig. 4. Certainty equivalents. The log of the certainty equivalent (in percentages on $y$-axis) is based on (15) and given for several investment horizons (in quarters on $x$-axis). It represents the annualized required monetary compensation for suboptimal investing of each invested dollar. The log certainty equivalent (solid line) is attributed to three components: return compensation (dashed line), liability hedge compensation (solid circled line) and risk diversification compensation (solid crossed line). This graph is based on a strategic investor with risky liabilities and risk aversion 20. Panel (a) shows the added value of credits, commodities, real estate and hedge funds: the investor chooses an optimal portfolio in an asset-liability context and an investment universe which is restricted to stocks and bonds. Panel (b) shows the certainty equivalent when the investor chooses the optimal portfolio in an asset-only context, instead of in an asset-liability context.

portfolio is higher than that of the restricted portfolio. Even though the optimal allocation to alternatives is preferred from an asset-liability perspective, it can lead to more stand-alone risk of the asset mix compared with a restrictive asset universe.

We do a second certainty equivalence calculation to determine the economic loss from choosing the strategic asset allocation in an asset-only context when the relevant criterion would be the asset-liability perspective. In the asset-liability framework, the investor explicitly maximizes the return of the asset mix in excess of the liabilities, rather than the return in excess of T-bills. Panel (b) in Fig. 4 shows that the annualized costs decrease with the investment horizon. Obviously the costs are positively related to risk aversion. A more risk averse investor puts more emphasis on the liability hedging qualities. 
Fig. 4 also provides insights into the sources of the required compensation. The compensation for missed liability hedge opportunities is substantial at all horizons and dominates the certainty equivalent. At medium and longer horizons, the attribution to the return enhancement component becomes important as well. The required compensation for lost return and liability hedge is partly undone by the lower risk of the asset-only portfolio. The asset-liability investor is worse off in terms of the stand-alone risk of the asset mix due to the longer duration. As a result, a portfolio which is preferred in mismatch risk terms is not necessarily optimal from an asset-only perspective.

Finally, we compare the gains from the long-horizon portfolios compared to the one-period portfolios. Fig. 5 shows gains from choosing the asset allocation in a strategic way instead of single-period portfolio choice for both an asset-only and an asset-liability investor. For horizons shorter than five years, gains are modest and equally large for asset-only as for asset-liability investors. For longer horizons the gains increase for both types of investors. They increase much more steeply, however, for the asset-liability investor. At the 25 years horizon, the gains for the asset-liability investor are almost double the gains of the asset-only investor. Due to long maturities of accrued pension obligations, pension funds do have such long planning horizons. We thus find that it is more important to be strategic when there are liabilities.

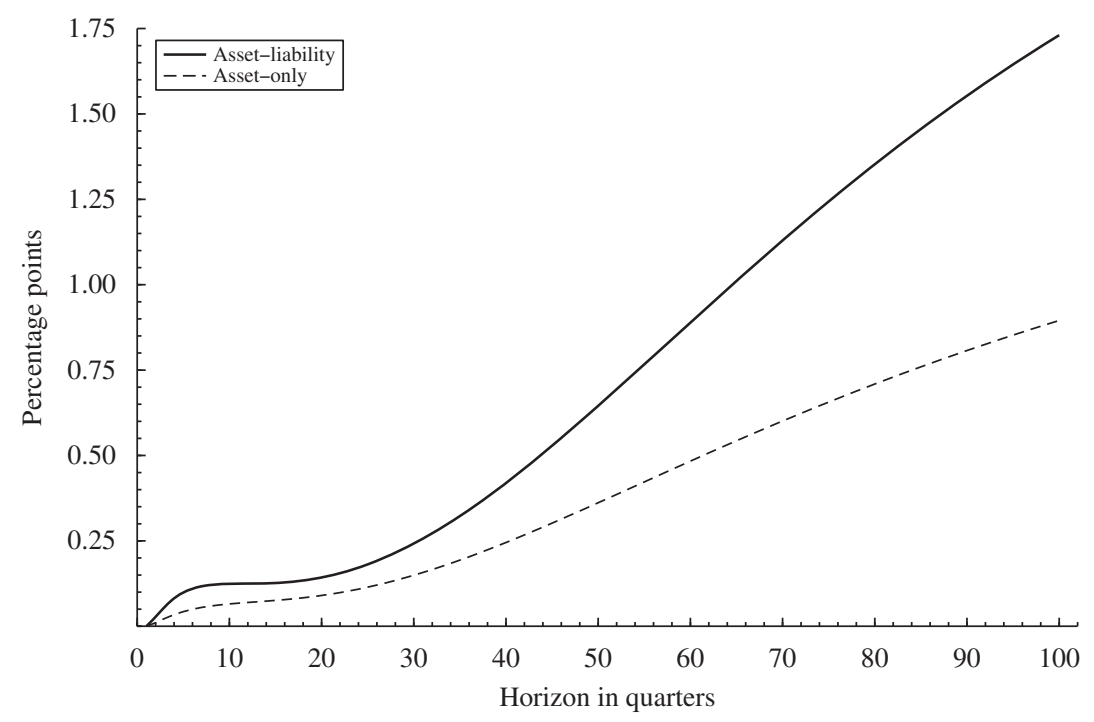

Fig. 5. Short-term versus long-term portfolio choice. The figure shows the benefits from long-term investing for an asset-liability (solid line) and an asset-only (dashed line) investor. Benefits are expressed as a certainty equivalent in simple terms (in percentages on $y$-axis) for different investment horizons (in quarters on $x$-axis). They represent the annualized percentage gains from being strategic $\left(\alpha^{(\tau)}\right)$ instead of choosing the asset allocation in a single-period context $\left(\alpha^{(1)}\right)$. The risk aversion parameter $\gamma=20$. The certainty equivalent is based on (15). 


\section{Conclusions}

This paper has explored which alternative asset classes add value for long-term investors as they have a term structure of risk that is markedly different from that of stocks and bonds. Commodities help in hedging inflation risk and have the best risk diversifying properties among the assets in our universe. Term structure properties of listed real estate and credits seem to a large extent captured by traditional asset classes. Hedge funds have good inflation hedging qualities in the long run, but a high exposure to stocks and bonds.

Differences in strategic portfolios for asset-only and asset-liability investors are due to differences in the global minimum variance and liability hedge portfolio. The main difference shows up in the attractiveness of short-term T-bills and long-maturity bonds. Asset-only investors have a large demand for short-term instruments due to their strong positive correlation with inflation at longer horizons. Although T-bills are a bad liability hedge, they remain attractive for their low risks at short horizons and good diversification properties with stocks and bonds at longer horizons. Bonds and credits are the best real rate hedge, and therefore have a large weight in the LHP. Commodities are in the LHP for their risk diversifying qualities. The LHP allocates a small amount to listed real estate and does not invest in hedge funds.

We find that the benefits of long-term investing are larger when there are liabilities. Apart from a different single-period portfolio, the asset-liability investor has different hedging demands at various horizons. In particular, asset-liability investors focus much more on interest rate risk and fixed-income products than asset-only investors. The diminishing correlation at longer horizons between stocks and bonds creates positive hedging demand for stocks in the LHP. In addition, asset-liability investors not only need to deal with reinvestment risks of T-bills, but also with duration mismatch risk with respect to the liabilities.

Various other issues that are relevant for portfolio choice have not been addressed in this paper. Among these, the form of the utility function of a multiple-member and multiple-objective pension plan deserves examination. Different dynamic portfolio choice frameworks could exploit the covariance structure differently. Also the implications of the intertemporal covariances in a broader asset-liability management context that adapts contributions, indexation, mortality risk and shortfall constraints deserves more scrutiny.

Similarly, we only considered the statistical properties of alternative investments. Investors sometimes do not invest in alternatives due to implementation issues, liquidity reasons, reputation risk or legal constraints. Implementation issues include advanced risk management with different requirements than for stocks and bonds, high entrance costs or high manager selection skills. Liquidity forms a restriction whenever the desired allocation to an asset class is not available in the market at realistic transaction costs. Reputation risk comes in as most institutional investors are evaluated and compared to their peers and competitors. An investor could be reluctant to invest in alternatives if his peers only invest in more traditional assets like stocks and bonds. Legal constraints could follow from rules which restrict investments to specific classes (e.g. no hedge funds allowed). 


\section{Acknowledgements}

We thank Michael Brandt, Frank de Jong, Rob van den Goorbergh, Joachim Inkmann, Ralph Koijen, Anthony Neuberger, Franz Palm and Luis Viceira for their comments. Our thanks also to two anonymous referees for their comments and suggestions. We acknowledge the financial support of the BSI Gamma Foundation.

\section{References}

Ackermann, C., McEnally, R., Ravenscraft, D., 1999. The performance of hedge funds: risk, return, and incentives. Journal of Finance 54, 833-874.

Agarwal, V., Naik, N.Y., 2000. Risks and portfolio decisions involving hedge funds. Review of Financial Studies 17, 63-98.

Bajeux-Besnainou, I., Jordan, J., Portait, R., 2003. Dynamic asset allocation for stocks, bonds and cash. Journal of Business 76, 263-287.

Barberis, N., 2000. Investing for the long run when returns are predictable. Journal of Finance 55, 389-406.

Bekaert, G., Hodrick, R.J., 2001. Expectations hypotheses tests. Journal of Finance 56, 1357-1394.

Van Binsbergen, J.H., Brandt, M.W., 2008. Optimal asset allocation in asset liability management. Working paper, Duke University.

Black, F., 1980. The tax consequences of long-run pension policy. Financial Analysts Journal July-August, 3-10.

Black, F., Litterman, 1992. Global portfolio optimization. Financial Analysts Journal 48, 28-43.

Blake, D., Cairns, A.J.G., Dowd, K., 2006. Living with mortality: longevity bonds and other mortalitylinked securities. British Actuarial Journal 12, 153-197.

Bodie, Z., 1983. Commodity futures as a hedge against inflation. Journal of Portfolio Management Spring, $12-17$.

Brandt, M.W., Santa-Clara, P., 2006. Dynamic portfolio selection by augmenting the asset space. Journal of Finance 61, 2187-2217.

Brennan, M.J., Xia, Y., 2002. Dynamic asset allocation under inflation. Journal of Finance 57, 1201-1238.

Brennan, M.J., Schwartz, E.S., Lagnado, R., 1997. Strategic asset allocation. Journal of Economic Dynamics and Control 21, 1377-1403.

Campbell, J.Y., Shiller, R.J., 1988. Stock prices, earnings and expected dividends. Journal of Finance 43, 661-676.

Campbell, J.Y., Shiller, R.J., 1991. Yield spreads and interest rate movements: a bird's eye view. Review of Economic Studies 58, 495-514.

Campbell, J.Y., Thompson, S., 2008. Predicting the equity premium out of sample: can anything beat the historical average? Review of Financial Studies, forthcoming.

Campbell, J.Y., Viceira, L.M., 2002. Strategic Asset Allocation: Portfolio Choice for Long-Term Investors. Oxford University Press, Oxford.

Campbell, J.Y., Viceira, L.M., 2005a. The term structure of the risk-return tradeoff. Financial Analysts Journal 61, 34-44.

Campbell, J.Y., Viceira, L.M., 2005b. Long-horizon Mean-variance Analysis: A User Guide, Unpublished Appendix. Harvard University.

Campbell, J.Y., Vuolteenaho, T., 2004. Bad beta, good beta. American Economic Review 94, 1249-1275.

Campbell, J.Y., Yogo, M., 2006. Efficient tests of stock return predictability. Journal of Financial Economics 81, 27-60.

Campbell, J.Y., Chan, Y.L., Viceira, L.M., 2003. A multivariate model for strategic asset allocation. Journal of Financial Economics 67, 41-80.

Campbell, J.Y., Chacko, G., Rodriquez, J., Viceira, L.M., 2004. Strategic asset allocation in a continuoustime VAR model. Journal of Economic Dynamics and Control 28, 2195-2214. 
Cochrane, J.H., 2008. The dog that did not bark: a defense of return predictability. Review of Financial Studies, forthcoming.

De Jong, F., Driessen, J., 2008. Liquidity Risk Premia in Corporate Bond Markets, Working paper, University of Amsterdam.

DeMiguel, V., Garlappi, L., Uppal, R., 2008. Optimal versus naive diversification: How inefficient is the $1 / \mathrm{N}$ portfolio strategy?, Review of Financial Studies, forthcoming.

Elton, E.J., Gruber, M.J., Agrawal, D., Mann, C., 2001. Explaining the rate spread on corporate bonds. Journal of Finance 56, 247-277.

Fama, E.F., 1981. Stock returns, real activity, and money. American Economic Review 71, 545-565.

Fama, E.F., French, K.R., 1989. Business conditions and the expected returns on stocks and bonds. Journal of Financial Economics 25, 23-49.

Froot, K.A., 1995. Hedging portfolios with real assets. Journal of Portfolio Management Summer, 60-77.

Fugazza, C., Guidolin, M., Nicodano, G., 2007. Investing for the long-run in European real estate. Journal of Real Estate Finance and Economics 34, 35-80.

Fung, W., Hsieh, D.A., 1997. Empirical characteristics of dynamic trading strategies: the case of hedge funds. Review of Financial Studies 10, 275-302.

Fung, W., Hsieh, D.A., 2000. Performance characteristics of hedge funds and commodity funds: natural vs. spurious biases. Journal of Financial and Quantitative Analysis 35, 291-307.

Geltner, D., 1991. Smoothing in appraised-based returns. Journal of Real Estate Finance and Economics 4, 327-345.

Geltner, D., 1993. Estimating market values from appraised values without assuming an efficient market. Journal of Real Estate Research 8, 325-345.

Gorton, G., Rouwenhorst, K.G., 2006. Facts and fantasies about commodity futures. Financial Analysts Journal 62, 47-68.

Goyal, A., 2004. Demographics, stock market flows, and stock returns. Journal of Financial and Quantitative Analysis 39, 115-142.

Goyal, A., Welch, I., 2003. Predicting the equity premium with dividend ratios. Management Science 49, 639-654.

Jorion, P., 1986. Bayes-Stein estimation for portfolio analysis. Journal of Financial and Quantitative Analysis 21, 279-292.

Kan, R., Zhou, G., 2007. Optimal portfolio choice with parameter uncertainty. Journal of Financial and Quantitative Analysis 42, 621-656.

Leibowitz, M.L., 1987. Pension asset allocation through surplus management. Financial Analysts Journal April, 29-40.

Leibowitz, M.L., Kogelman, S., Bader, L.N., 1994. Funding ratio return. Journal of Portfolio Management Fall, 29-47.

Lioui, A., Poncet, P., 2001. On optimal portfolio choice under stochastic interest rates. Journal of Economic Dynamics and Control 25, 1841-1865.

Litterman, R., 2003. Modern Investment Management: An Equilibrium Approach. Wiley.

Michaud, R., 1989. The Markowitz optimization enigma: is optimized optimal? Financial Analysts Journal 45, 31-42.

Pastor, L., Stambaugh, R.F., 2000. Comparing asset pricing models: an investment perspective. Journal of Financial Economics 56, 335-381.

Posthuma, N., Van der Sluis, P.-J., 2003. A Reality Check on Hedge Fund Returns. Research Memorandum Vrije University Amsterdam.

Poterba, J., 2001. Demographic structure and asset returns. Review of Economics and Statistics 83, $565-584$.

Schotman, P.C., Schweitzer, M., 2000. Horizon sensitivity of the inflation hedge of stocks. Journal of Empirical Finance 7, 301-315.

Sharpe, W.F., Tint, L.G., 1990. Liabilities: a new approach. Journal of Portfolio Management Winter, $5-10$.

Stambaugh, R.F., 1997. Analysing investments whose histories differ in length. Journal of Financial Economics 45, 285-331. 
Stambaugh, R.F., 1999. Predictive regressions. Journal of Financial Economics 54, 375-421.

Sundaresan, S., Zapatero, F., 1997. Valuation, optimal asset allocation and retirement incentives of pension plans. Review of Financial Studies 10, 631-660.

Tepper, I., 1981. Taxation and corporate pension policy. Journal of Finance 36, 1-13.

Wachter, J., 2002. Optimal consumption and portfolio allocation under mean-reverting returns: an exact solution for complete markets. Journal of Financial and Quantitative Analysis 37, 63-91.

Wachter, J., Warusawitharana, M., 2008. Predictable returns and asset allocation: should a skeptical investor time the market? Working paper, University of Pennsylvania. 